\title{
LIQUEFACTION EFFECTS AND ASSOCIATED DAMAGES OBSERVED AT THE WELLINGTON CENTREPORT FROM THE 2016 KAIKOURA EARTHQUAKE
}

\author{
Misko Cubrinovski ${ }^{1}$, Jonathan D. Bray ${ }^{2}$, Christopher de la Torre ${ }^{3}$, \\ Michael J. Olsen ${ }^{4}$, Brendon A. Bradley ${ }^{5}$, Gabriele Chiaro ${ }^{6}$, \\ Emilia Stocks ${ }^{7}$ and Liam Wotherspoon ${ }^{8}$
}

(Submitted April 2017; Reviewed April 2017; Accepted May 2017)

\begin{abstract}
Widespread liquefaction occurred in the end-dumped gravelly fills and hydraulically-placed dredged sandy fill at the CentrePort of Wellington as a result of the 14 November $2016 M_{\mathrm{w}} 7.8$ Kaikoura earthquake. This liquefaction resulted in substantial global (mass) settlement and lateral movement (spreading) of the fills towards the sea, which adversely affected wharf structures and buildings constructed on shallow and deep foundations. This paper presents key observations from the QuakeCoRE-GEER post-earthquake reconnaissance efforts at the CentrePort Wellington. The different materials and methods used to construct the reclaimed land at CentrePort influenced the patterns of observed liquefaction and its effects. Areas of gravel liquefaction at the port are especially important due to the limited number of these case histories in the literature. Liquefaction-induced ground deformations caused the wharves to displace laterally and damage their piles and offloading equipment. Lateral ground extension and differential settlement damaged buildings, whereas buildings in areas of uniform ground settlement without lateral extension performed significantly better.
\end{abstract}

\section{INTRODUCTION}

The port of Wellington (CentrePort Limited, herein called CentrePort) experienced significant liquefaction of reclaimed land and liquefaction-induced ground deformations that led to wharf and building damage in the $M_{w} 7.8$ Kaikoura earthquake. The liquefaction caused global settlement of the fill deposits and lateral movement of the fills towards the sea. There was evidence of lateral spreading in the fills behind the pilesupported wharves and liquefaction-induced settlement in the soils surrounding buildings supported on shallow and deep foundations. Following the Kaikoura earthquake, the QuakeCoRE-GEER team performed on-site reconnaissance on November 17, 20, 21, 22, 23 and 30, and December 1 and 2, 2016. This paper summarises key observations from the field surveys and focuses on the geotechnical aspects of the earthquake and its impacts at the port. The paper first provides background information on the CentrePort reclamations and recorded ground motions during the earthquake, and then focuses on observations of liquefaction manifestation and consequent ground deformation as well as geotechnical aspects of the seismic performance of wharf and building structures. Further details on the reconnaissance may be found in [1]. An overview of liquefaction observations in the area of Wellington outside of the port is presented in [2].

\section{CHARACTERISTICS OF RECLAIMED LAND AT THE PORT}

CentrePort is located in central Wellington (Figure 1). The historical development of Wellington Harbour land reclamation in the vicinity of CentrePort is illustrated in Figure 2. In this figure, the original coastline in the 1850s is shown with the dashed line, and areas of different stages of reclamations are indicated. A large portion of the current port area was reclaimed in the final phase of reclamations between 1965 and 1975 when the Thorndon Container Terminal and Thorndon Wharf were constructed. Some of the old structures from previous reclamation stages remained in place during subsequent reclamation works either as part of the current port facilities or as remnants of abandoned structures that were left in place during subsequent reclamations. The most important structures in this context are Kings Wharf, Pipitea Wharf, and the mass concrete Old Seawall, all of which are indicated in Figure 2. Kings Wharf was completed in 1906 and is part of the current port facilities, whereas the Pipitea Wharf, which was completed in 1930, was partially demolished during Stage 3 (1965-1975 period) reclamation works, but its piles and portions of the deck were left in place and are now buried in the reclaimed land. Similarly, the Old Seawall, which is aligned in the southwest to northeast direction (Figures 2 and 3), is still in place and is part of the current reclamation. These structures are important references with regard to the characteristics of the reclaimed soils, because different soils and reclamation techniques were used in different stages of the reclamation works.

\footnotetext{
1 Corresponding Author, Professor, Department of Civil and Natural Resources Engineering, University of Canterbury, Christchurch, NZ misko.cubrinovski@canterbury.ac.nz (Member)

2 Professor, Department of Civil and Environmental Engineering, University of California, Berkeley, CA, USA jonbray@berkeley.edu

3 PhD Student, Department of Civil and Natural Resources Engineering, University of Canterbury, NZ christopher.delatorre@pg.canterbury.ac.nz

4 Associate Professor, School of Civil and Construction Engineering, Oregon State University, USA michael.olsen@oregonstate.edu

5 Professor, Department of Civil and Natural Resources Engineering, University of Canterbury, NZ, brendon.bradley@canterbury.ac.nz (Member)

${ }^{6}$ Lecturer, Department of Civil \& Natural Resources Engineering, University of Canterbury, NZ, gabriele.chiaro@canterbury.ac.nz (Member)

7 Geotechnical Engineer, Tonkin and Taylor Ltd, Wellington, NZ estocks@tonkintaylor.co.nz

8 Senior Lecturer, Department of Civil and Environmental Engineering, University of Auckland, l.wotherspoon@auckland.ac.nz (Member)
} 


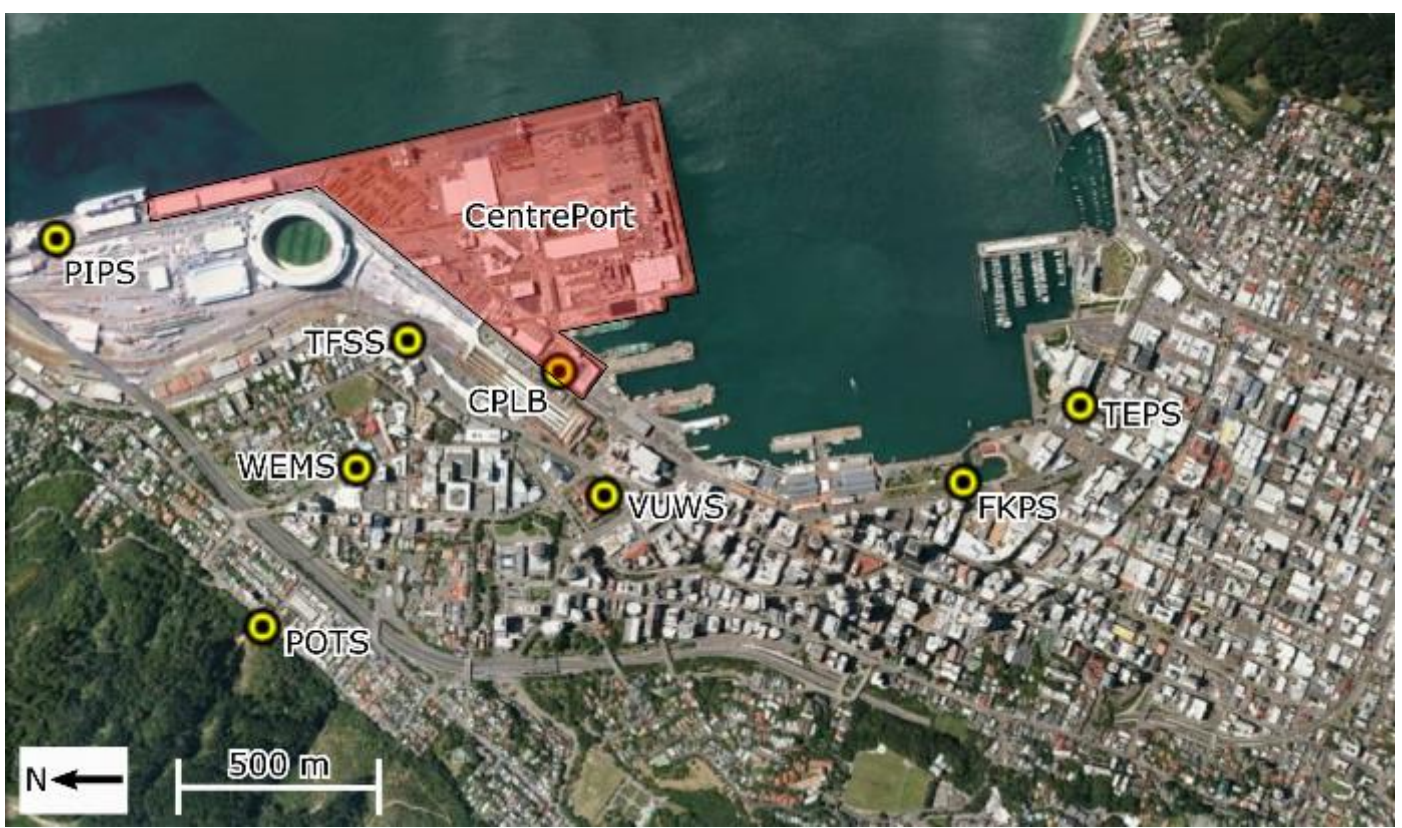

Figure 1: Aerial view of Wellington highlighting CentrePort. The location of strong motion stations near CentrePort Wellington that recorded the Kaikoura earthquake are also shown (Base image from Google Earth ${ }^{T M}$ ).

\section{Construction of CentrePort Reclamation}

Two methods of reclamation were used primarily to construct the reclaimed land at CentrePort: (a) end-dumping (tipping) of gravelly soils from truck and barge operations using soils from quarries in the Wellington region; and (b) hydraulically placing fill using dredged material from the original seabed in the vicinity of the reclamation works. Figure 3 shows that hydraulic fills were constructed along the waterfront north of the Old Seawall whereas the majority of the reclaimed land at CentrePort was constructed by the end-tipping method. Importantly, a relatively small volume (i.e., about $250,000 \mathrm{~m}^{3}$ ) of the Thorndon Reclamation may have been constructed using dredged material from the harbour entrance $[3,4]$.

As summarised in Figure 3, reclaimed land that is south of the Old Seawall is generally composed of gravelly soils with an age of approximately 40 years, with a possible exception for a relatively small volume of dredged material mentioned above. The age of similar end-tipped gravelly reclamations north of the Old Seawall is about 100 years. The hydraulic fills, located north of the Old Seawall, are about 80 years old and predominantly composed of sand and silt dredged from the original seabed. Note that based on available historical records and technical reports, it is difficult to establish the precise location of the boundaries between hydraulic fills and endtipped reclamations north of the seawall. Hence, the delineation shown in Figure 3 indicates the approximate location of these boundaries.

The characteristics of the materials used for the Thorndon Reclamation are summarized below [12]:

- The reclamation was constructed using "common fill." By specification, the "common fill" was gravelly soil with sand, some cobbles, and some fines; the maximum dimension of the cobbles was $150 \mathrm{~mm}$ (with particles larger than boulders randomly permitted); soils passing the 0.036 $\mathrm{mm}$ sieve should be either non-plastic or have a Plasticity Index (PI) value not greater than 5 .
- A rockfill "filter" layer and overlying rockfill armour layer were placed along the edges of the slopes of the "common fill" to provide coastal protection. The rock material used for the filter was specified as a uniform material graded between $25 \mathrm{~mm}$ and $125 \mathrm{~mm}$ in diameter with up to $5 \%$ undersize material and up to $10 \%$ oversize material (up to a maximum of $300 \mathrm{~mm}$ in diameter). The rockfill armour was constructed of "C-grade rock" (evenly graded rock between $22 \mathrm{~kg}$ and $90 \mathrm{~kg}$ ) and "A-grade rock" (graded between 90 $\mathrm{kg}$ and $700 \mathrm{~kg}$, with at least $60 \%$ of the supplied rock being over $450 \mathrm{~kg}$ ). The "A-grade rock" was placed into position by a crane (i.e., it was not dropped).

The construction involved the following key stages and features:

- Prior to placement of the "common fill" material, the seabed was dredged to remove the soft sediments.

- Approximately 2,900,000 $\mathrm{m}^{3}$ of "common fill" from the quarries were dumped by end-tipping to construct the Thorndon Reclamation. An additional $250,000 \mathrm{~m}^{3}$ of dredged material were also used in this reclamation.

- To place the protective armour rock, small (i.e., about 6 meters wide) rock mounds were built near the toe of the "common fill" reclamation to restrain laterally the rock as it was placed over the sloped face of the reclamation fill.

- Fill was not compacted below the water level. Once the reclaimed ground reached $0.9 \mathrm{~m}$ above the water table, the soils were compacted to support the pavement. Static rollers (without vibration) were used to compact the fills in layers less than $0.23 \mathrm{~m}$ thick above the water table (WT). This created a compacted crust about $1.5 \mathrm{~m}$ to $2.0 \mathrm{~m}$ thick below the pavement

- The reclamation was covered by asphalt pavement overlying a base course. The thickness of the pavement varies across the reclamation area and is predominantly 0.2 $\mathrm{m}$ to $0.3 \mathrm{~m}$ thick, whereas the base course is about $0.5 \mathrm{~m}$ thick. 


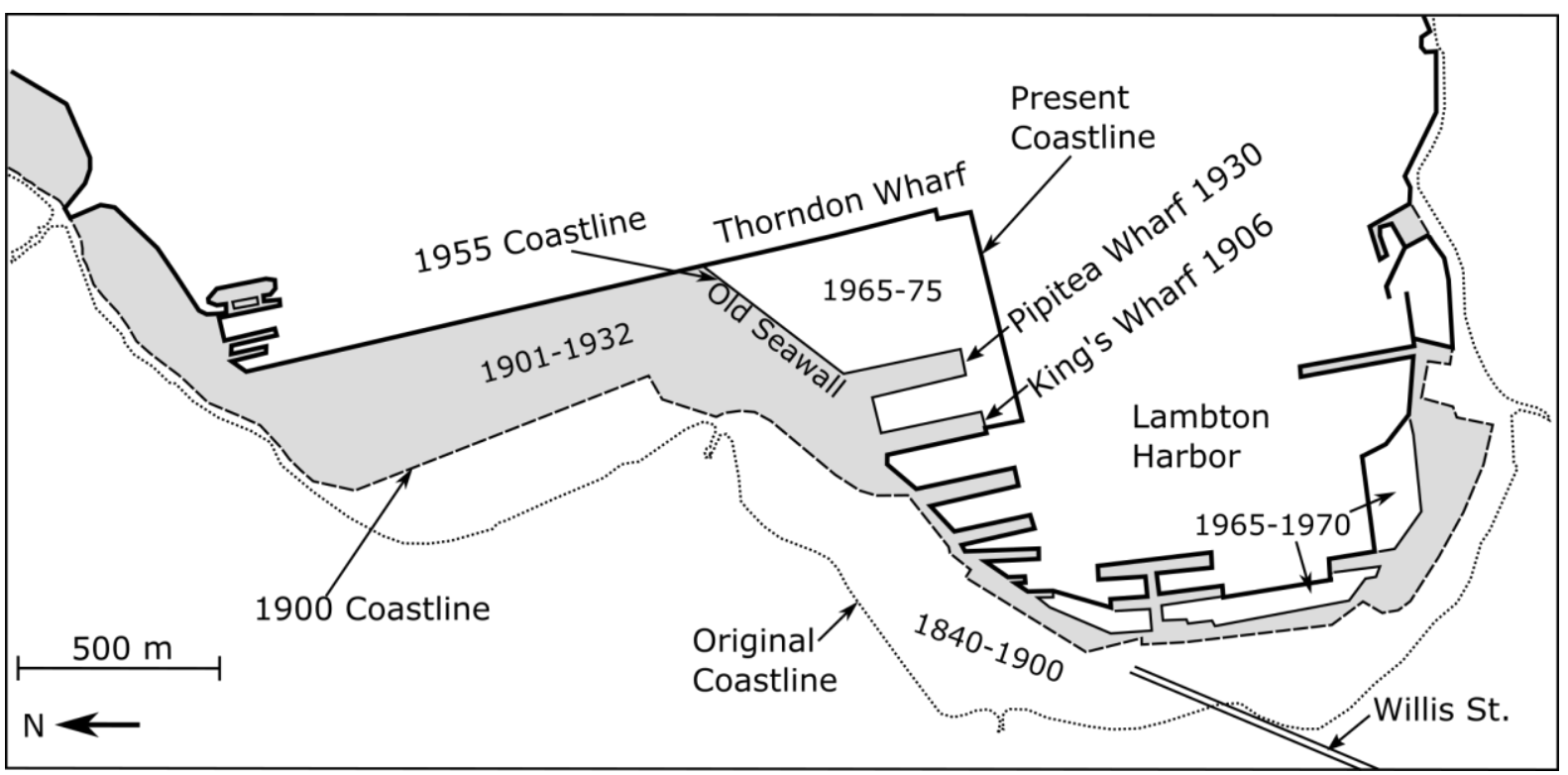

Figure 2: Historical development of land reclamation in the Wellington Harbour (based on maps from Anderson [5]).

\section{Characteristic Layers at CentrePort}

The characteristic soil profile at the Thorndon Reclamation consists of the following layers:Compacted earth fill and pavement layer, which is typically:

- about 2.0 to $3.0 \mathrm{~m}$ thick. This layer was above the water table during construction.

- Un-compacted reclamation fill (below the WT during construction), which varies between $10 \mathrm{~m}$ and $18 \mathrm{~m}$ thick.

- Marine deposits of interbedded sand/clay/silty clay, or soft to very stiff clay, which are relatively thin layers with a total thickness of about $1 \mathrm{~m}$ to $2.5 \mathrm{~m}$.

- Wellington Alluvium, which is an approximately 200-m thick layer composed of interbedded dense gravel and stiff to very stiff silt.

- Greywacke sandstone/siltstone bedrock, which is estimated to be $200 \mathrm{~m}$ to $250 \mathrm{~m}$ deep.

The thickness of the reclaimed deposit is variable depending on the horizontal distance from the original coastline (or depth to the original seabed). It is approximately $10 \mathrm{~m}$ to $15 \mathrm{~m}$ thick at the location of the buried mass concrete Old Seawall (Figures 2 and 3) and increases to approximately $18 \mathrm{~m}$ to $20 \mathrm{~m}$ thickness at the southern-most end of the Thorndon Reclamation. Underlying the reclamation fill is a relatively thin marine deposit, which is underlain by Wellington Alluvium. Characteristic cross-sections that illustrate the key soil layers and their thicknesses are shown in Figure 4. These crosssections and the soil borings used to develop them run through the fills in the N-S direction just behind the King's Wharf (Figure 4a) and Thorndon Wharf (Figure 4b). Mean high water (MHW) is approximately 3 meters below the existing pavement surface.

Standard Penetration Test (SPT) blow count data are provided in the soil exploratory borings conducted at CentrePort [4, 6-8]. However, the SPT procedures employed during the previous site investigations are not always described sufficiently to ascertain if the recorded SPT $N$ values are actually standard $N_{60}$ values (i.e., corresponding to $60 \%$ free-fall energy). Moreover, some of the SPT data were obtained by non-standard SPT procedures using a solid cone instead of a split-spoon sampler. With these limitations in mind, $N$ values of the un-compacted gravelly fill range from approximately 5 to 15 blows $/ 300 \mathrm{~mm}$. In the compacted fill layer above MHW, $\mathrm{N}$-values generally range between 13 and 50+ blows/300 $\mathrm{mm} \mathrm{[4,9].} \mathrm{SPT} N$ values of the soil layers from some of the available borings are indicated in the simplified cross-sections shown in Figure 4.

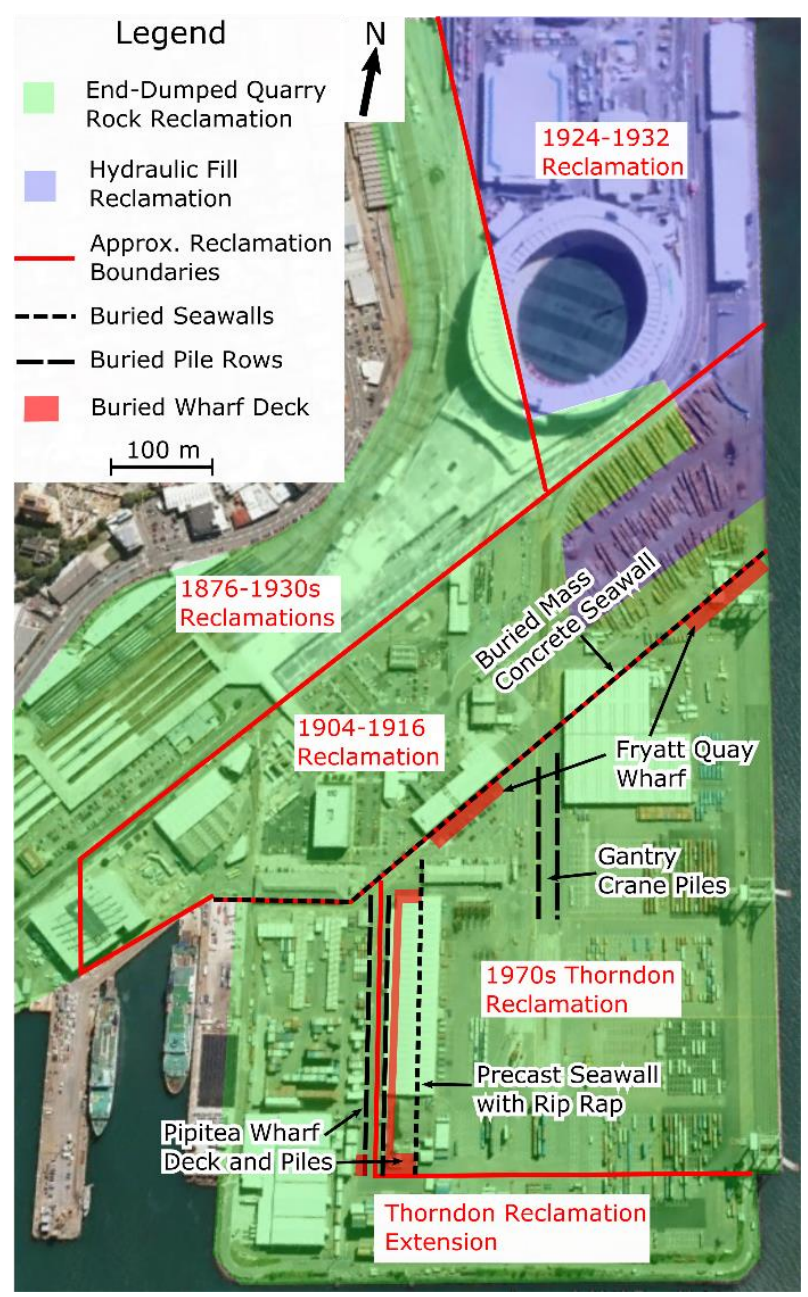

Figure 3: Approximate boundaries of various land reclamations at CentrePort Wellington with reference to existing and old structures and different methods and periods of reclamation construction $[3,4,10,11]$ (Base image from Google Earth ${ }^{T M}$ ). 
(a)

Horizontal Distance $(\mathrm{m})$

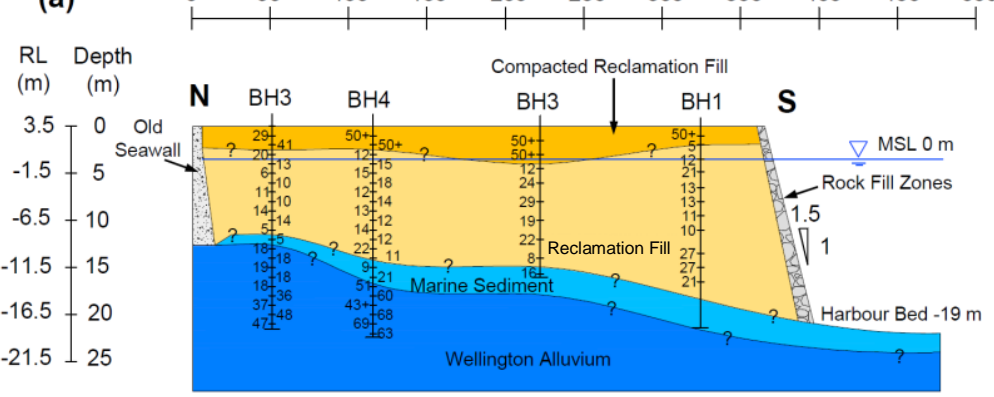

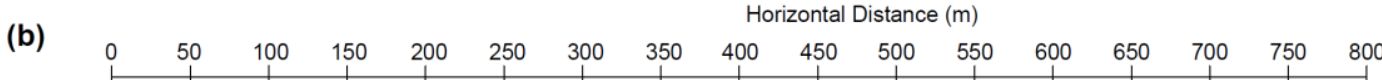

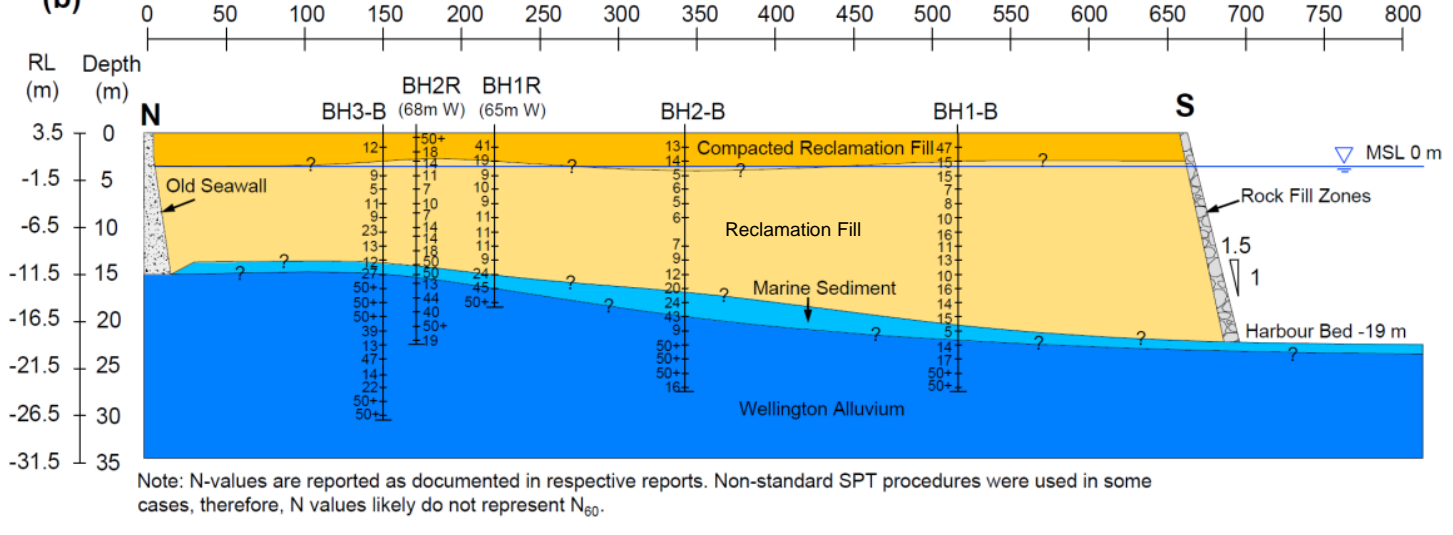

Figure 4: Schematic soil cross sections illustrating key layers and their thicknesses at CentrePort; note the different horizontal and vertical scales for the cross sections; (a) N-S Cross section east of King's Wharf; (b) $\mathrm{N}-\mathrm{S}$ Cross section west of Thorndon's Wharf.

Figure 5 shows grain-size distribution curves for samples collected (prior to the Kaikoura earthquake) from subsurface explorations at locations approximately 5 to $40 \mathrm{~m}$ west of Thorndon Wharf. The fill is composed of gravelly soil including $10 \%$ to $40 \%$ sand and fines content of less than $15 \%$. Comparative grain-size distribution curves for samples of the marine deposits are also shown in Figure 5. The test data indicate the marine deposits are predominantly sandy soils with fines content in the range between $15 \%$ and $35 \%$.

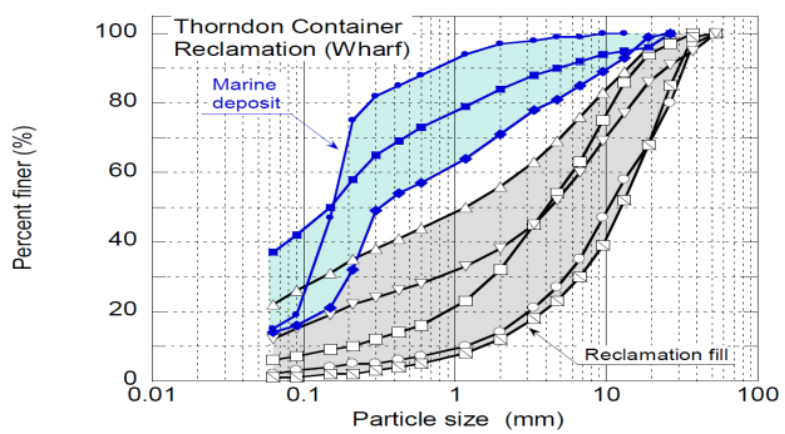

Figure 5: Grain-size distribution curves for borehole samples of the reclaimed fill and marine deposit.

\section{RECORDED GROUND MOTIONS}

Ground motions generated by the 2016 Kaikoura earthquake were recorded by a relatively dense array of strong motion stations (SMS) in Wellington as discussed further by Bradley et al. [12]. Figure 1 shows the locations of eight SMS that recorded the event near CentrePort Wellington. A summary of important information for the recorded accelerations and characteristics of the sites is given in Table 1, which includes: geometric mean horizontal peak ground acceleration (HPGA) recorded at the SMS during the 2016 Kaikoura earthquake, cyclic stress ratios at the water table (CSR $\mathrm{CS}_{w t}$, which is discussed later), site class per NZS1170.5 [13], and site period estimates based on horizontal-to-vertical spectral ratios from all strong motions in the GeoNet database with PGA less than $0.15 \mathrm{~g}$.

The QuakeCoRE-GEER team inspected each of these SMS sites. There was no evidence of liquefaction manifestation in the form of sediment ejecta at the ground surface at any of these SMS sites. The CPLB station is located at the B building, the perimeter of which was documented in brief walk-through inspections. Minor settlement of the surrounding soil relative to the B building was observed at some locations, but settlement of the ground relative to the building was otherwise negligible to minor. There was no evidence of significant ground deformation at any of the other SMS sites.

No ground motion records were obtained directly at the Thorndon Reclamation of CentrePort, with the CPLB and TFSS stations being the closest to CentrePort at distances of about 200 $\mathrm{m}$ west and $500 \mathrm{~m}$ northwest of the Thorndon Reclamation, respectively. Figure 6 shows ground surface acceleration-time traces in three orthogonal directions recorded at CPLB and TFSS. The recorded PGAs at soil sites are generally between $0.15 \mathrm{~g}$ and $0.25 \mathrm{~g}$ (Table 1), and acceleration-time traces show a relatively large number of strong amplitude cycles (i.e., indicative of long significant duration), which is consistent with the large magnitude of the event $\left(M_{\mathrm{W}}=7.8\right)$.

Station POTS is a rock site located about $1.0 \mathrm{~km}$ northwest from CentrePort. Thus, it is valuable as a reference site for investigation of basin effects and local soil response (site effects) on the recorded motions in the Kaikoura event. It could also be beneficial for performing seismic site response analyses of various sites (including SMS sites) at which nonlinearity and excess pore water pressures may have significantly influenced their response. 

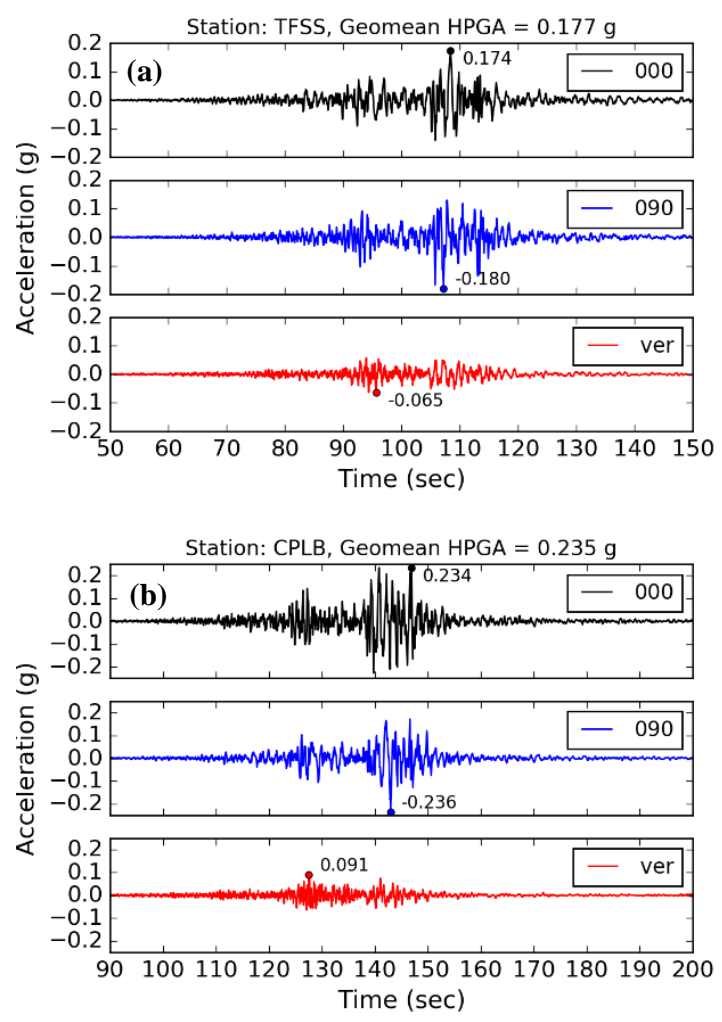

Figure 6: Acceleration traces from (a) TFSS station and (b) $C P L B$ station recordings.

Figure 7 shows the geometric mean, 5\%-damped, acceleration response spectra for the eight SMS sites considered, grouped in terms of site characteristics as: rock (POTS), natural soil deposit (VUWS, WEMS), and reclaimed soil sites (PIPS, TFSS, CPLB, FKPS, TEPS). The FKPS and TEPS spectra may be affected by the Te Aro Basin as opposed to the Thorndon Basin at the CentrePort and nearby SMS sites. The spectra reflect the combined effects of several source, path, and site factors which should be considered when interpreting the recorded ground motions. The comparative plots show strong amplification of amplitudes at both natural and reclaimed sites as compared to the recorded rock accelerations across all periods up to 4 seconds. The amplification is particularly pronounced in the range between $\mathrm{T}=1.0 \mathrm{~s}$ and $2.0 \mathrm{~s}$, and for this and greater periods is more pronounced at the reclaimed sites located along or closer to the waterfront. Further research is needed to understand the influence of the reclamation layer in conjunction with deeper sediment depths at these sites relative to shallower native soil sites. The geometric mean spectra are also compared to the design spectrum from NZS1170.5 [13] for Site Class D in Figure 7. Observed ground motions exceeded this design spectrum only at periods between approximately 1 and 2 seconds for two sites on reclaimed soil and are significantly less than the design spectrum at periods shorter than 1 seconds and longer than 2 seconds.

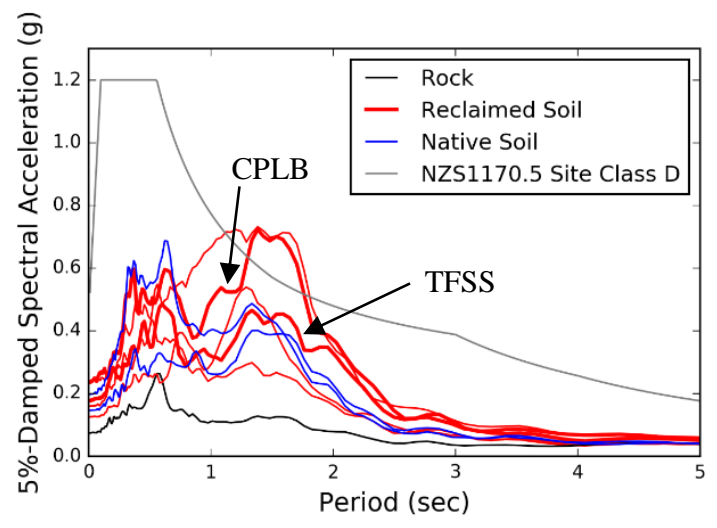

Figure 7: Acceleration response spectra (5\% damped) for rock, natural deposits, and reclaimed soils sites compared to the NZS1170.5 design spectrum [13]. TFSS and CPLB are shown in bold red.

\section{SEISMIC DEMAND FOR LIQUEFACTION ASSESSMENT}

In the widely used simplified liquefaction triggering procedures (e.g., Boulanger and Idriss [14]), a factor of safety against liquefaction triggering is estimated as:

$F S=\frac{C R R_{7.5,101}}{C S R} M S F \times K_{\sigma}$

in which $\mathrm{CRR}_{7.5,101}$ is the Cyclic Resistance Ratio for a $M_{w} 7.5$ event and an effective overburden stress of $101 \mathrm{kPa}$ (atmospheric pressure) at a level ground site, MSF is the magnitude scaling factor, $K_{\sigma}$ is overburden stress correction factor, and CSR is the Cyclic Stress Ratio, which is a proxy for the amplitude of the seismic demand. CSR is a function of the PGA at the ground surface, the ratio of the total and effective vertical stresses, the depth within the deposit, and the depth below the water table, i.e. CSR $=\mathrm{f}\left[P G A, \sigma_{v o} / \sigma_{v o}^{\prime}, r_{d}(z), z_{w t}\right]$. For shallow depths at the water table, the depth dependent factors are equal to unity (i.e., there are no effects of soil flexibility [ $\left.\mathrm{r}_{d}=1.0\right]$, or water table depth on CSR [ $\left.\mathrm{f}\left(\mathrm{z}_{w t}\right)=1.0\right]$, and $\sigma_{v o} / \sigma_{v o}^{\prime}=1.0$ at the water table). Hence, the cyclic stress

Table 1: Strong motion stations near CentrePort with geometric mean PGA for the 2016 Kaikoura earthquake and site characterisation metrics.

\begin{tabular}{cccccc}
\hline Station ID & $\begin{array}{c}\text { Kaikoura EQ } \\
\text { Geomean HPGA } \\
(\mathbf{g})\end{array}$ & $\begin{array}{c}\text { CSR }_{\text {wt }}= \\
\mathbf{0 . 6 5} \text { PGA/g }\end{array}$ & $\begin{array}{c}\text { NZS1170.5 } \\
\text { Site Class }\end{array}$ & $\begin{array}{c}\text { Site Period } \\
\text { Estimate } \\
(\mathbf{s e c})\end{array}$ & Site (soil) type \\
\hline POTS & 0.074 & - & $\mathrm{B}$ & - & Rock \\
\hline TFSS & 0.177 & 0.11 & $\mathrm{D}$ & 1.3 & Natural soil deposit \\
\hline WEMS & 0.146 & 0.09 & $\mathrm{D}$ & 0.80 & Natural soil deposit \\
\hline CPLB & 0.235 & 0.15 & $\mathrm{D}$ & 1.2 & Reclaimed soil \\
\hline VUWS & 0.198 & 0.13 & $\mathrm{D}$ & 0.75 & Reclaimed soil \\
\hline TEPS & 0.126 & 0.08 & $\mathrm{D}$ & 1.0 & Reclaimed soil \\
\hline FKPS & 0.159 & 0.10 & $\mathrm{D}$ & 1.0 & Reclaimed soil \\
\hline PIPS & 0.240 & 0.16 & Unknown & $>2$ & Reclaimed soil \\
\hline
\end{tabular}


ratio is effectively a function of the PGA alone. With these simplifications in mind, the cyclic stress ratio at a shallow depth of the water table $\left(\mathrm{CSR}_{w t}\right)$ can be approximated with Equation 2 using the geometric mean peak ground accelerations $\left(\mathrm{a}_{\max }\right)$ recorded in the horizontal directions at the strong motion stations:

$C S R_{w t}=0.65 \frac{a_{\max }}{g}$

The estimated CSR $\mathrm{R}_{w t}$ values for the SMS sites are summarized in Table 1. $\mathrm{CSR}_{w t}=0.11-0.16$ for the three SMS sites closest to the port (i.e., CPLB, TFSS, and PIPS). This demand in terms of CSR is illustrated in Figure 8 together with the equivalent sand liquefaction resistance (CRR7.5,101) as a function of the SPT blow count (shown with the solid line), as defined in the semi-empirical liquefaction evaluation procedure of Boulanger and Idriss [15]. Note that the product of $M S F \times K_{\sigma}$ in Equation (1) is approximately 1.0 for the combination of $M_{w} 7.8$ earthquake and an effective overburden stress of about $\sigma_{v o}^{\prime}=$ 40 to $60 \mathrm{kPa}$ corresponding to a water table depth of $2 \mathrm{~m}$ to 3 $\mathrm{m}$. Thus, the computed $\mathrm{CSR}_{w t}$ can be directly compared to the liquefaction resistance expressed in terms of CRR7.5,101 shown in Figure 8. If one accounts for the conservativism in this deterministic relationship of CRR 7.5,101, which corresponds to a $15 \%$ liquefaction probability [14], then the plot roughly indicates that the seismic demand was sufficient to trigger liquefaction in deposits having an equivalent clean sand SPT blow count of less than 10 to 14 blow counts. This simplified estimate of seismic demand applies to the soil at the depth of the ground water table and serves only as a rough indicator of the imposed seismic demand for assessing liquefaction triggering. The Boulanger and Idriss [15] CRR correlation was developed based on case histories on sandy soils, and therefore its applicability to gravelly soils is affected by several factors including the conversion of the penetration resistance of gravelly soils to an equivalent clean sand blow count. Hence, the plot shown in Figure 8 is only an indicator of the seismic demand in relative terms (i.e., in relation to an equivalent clean sand liquefaction resistance), and further research is needed to determine directly the cyclic resistance of the reclaimed deposits.

\section{LIQUEFACTION-INDUCED LAND DEFORMATION}

The first QuakeCoRE-GEER team survey at CentrePort was conducted on 17 November 2016 (three days after the Kaikoura earthquake), when most of the liquefaction evidence remained on the ground surface. These inspections covered most of the port area and focused on documenting perishable data, which included documenting and collecting soil ejecta, measurements of vertical offsets and horizontal ground movements along selected transects, and documenting observed wharf and building damage. Subsequent surveys were performed from 20 November to 2 December, which focused on obtaining additional evidence and measurements of ground movements and relative movements between the wharves or buildings and the surrounding soils. In the later part of this period, groundbased LiDAR scanning was conducted along transects of the reclamations as well as around and within structures of interest. The observations and measured values (approximate values obtained from measurements during the inspections) presented in this paper were obtained from the above field reconnaissance activities, if not stated otherwise.

\section{Liquefaction Manifestations}

Relatively widespread liquefaction was observed in both the end-dumped quarry fill and hydraulically-placed dredged fill. Liquefaction was manifested in various forms either directly as soil ejecta on the pavement surface of the port or indirectly in the form of vertical and horizontal ground movements, which

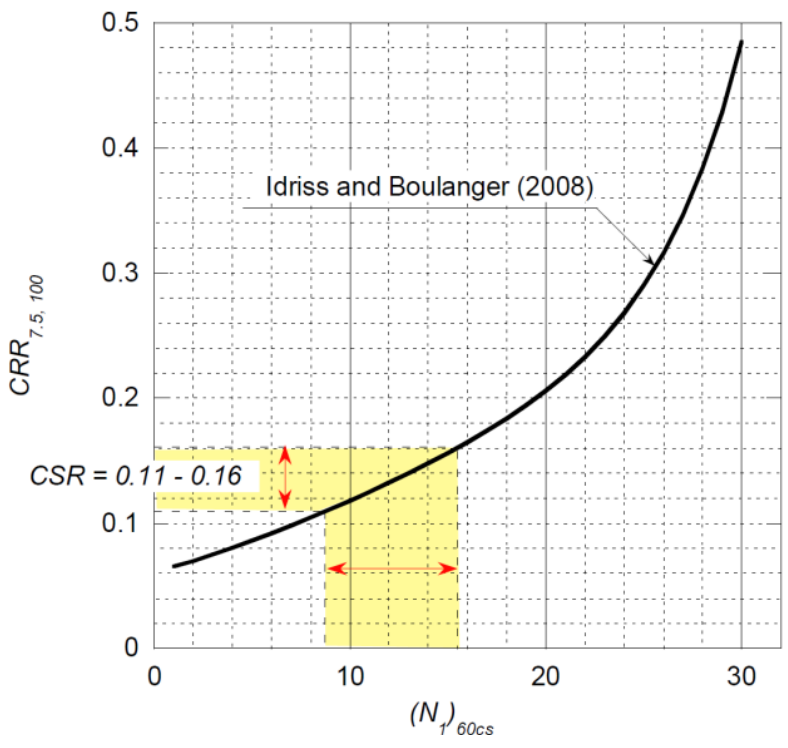

Figure 8: Illustration of seismic demand induced by the 2016 Kaikoura earthquake for assessing liquefaction triggering at depth of the water table for the three sites on reclaimed soils in the vicinity of the port (i.e., PIPS, TFSS and CPLB).

were often accompanied by ground cracks and fissures, and vertical offsets, especially along the interface zones with wharves and buildings. From these general observations, one could infer a substantial global (mass) settlement across much of the reclamation and lateral movement (spreading) of the fills towards the sea. The lateral movements and associated ground distress were generally more pronounced along the edges of the reclamation. The ground movements affected the wharves and buildings at CentrePort in various ways, as discussed in the subsequent sections of this paper.

Liquefaction was most evidently manifested by ejected soils on the paved surface of the port. The areas covered by ejecta were scattered and somewhat non-uniform both in their spatial distribution and thickness of the ejected soils. The manifestations of liquefaction varied from traces of ejected soil and water to larger volumes of ejecta with thicknesses of up to 150-200 mm. The latter were typically found near cracks and fissures through which the liquefied soils reached the ground surface. In a few isolated cases, a larger amount of ejecta was observed near partially collapsed pavement and cavities, or along existing drainage conduits beneath the pavement.

The ejected soils shown in Figure 9 in the area south of the Old Seawall (i.e., in the area of the end-tipped 'common fill' reclamation) consisted of gravelly soils including some cobblesized particles. There was one notable exception in this regard, where a smaller area of the Thorndon Container Terminal was covered by uniform sand ejecta (Figure 10). Sand ejecta were also observed in the hydraulically-placed fill of the Log Yard, north of the Old Seawall (Figure 11).

Thirteen samples of ejecta were collected on 17 November at the locations shown in Figure 12 (samples S1-S13). Sand liquefaction ejecta were observed at three different areas: (1) the Thorndon container stacking area at samples S11 and S12 (Figure 10); (2) immediately upland of the buried mass concrete seawall at sample S2; and (3) the log stacking area at sample S13 (Figure 11). Interestingly, only the log stacking area at S13 coincides with an area shown previously to have sandy hydraulically-placed dredged fill (i.e., purple shaded area in Figure 3). Gravelly liquefaction ejecta were present over large portions of the Thorndon Reclamation and Thorndon Reclamation Extension. This material is the end-dumped quarry rock referred to above as "common fill." The remaining samples were collected from this material. 

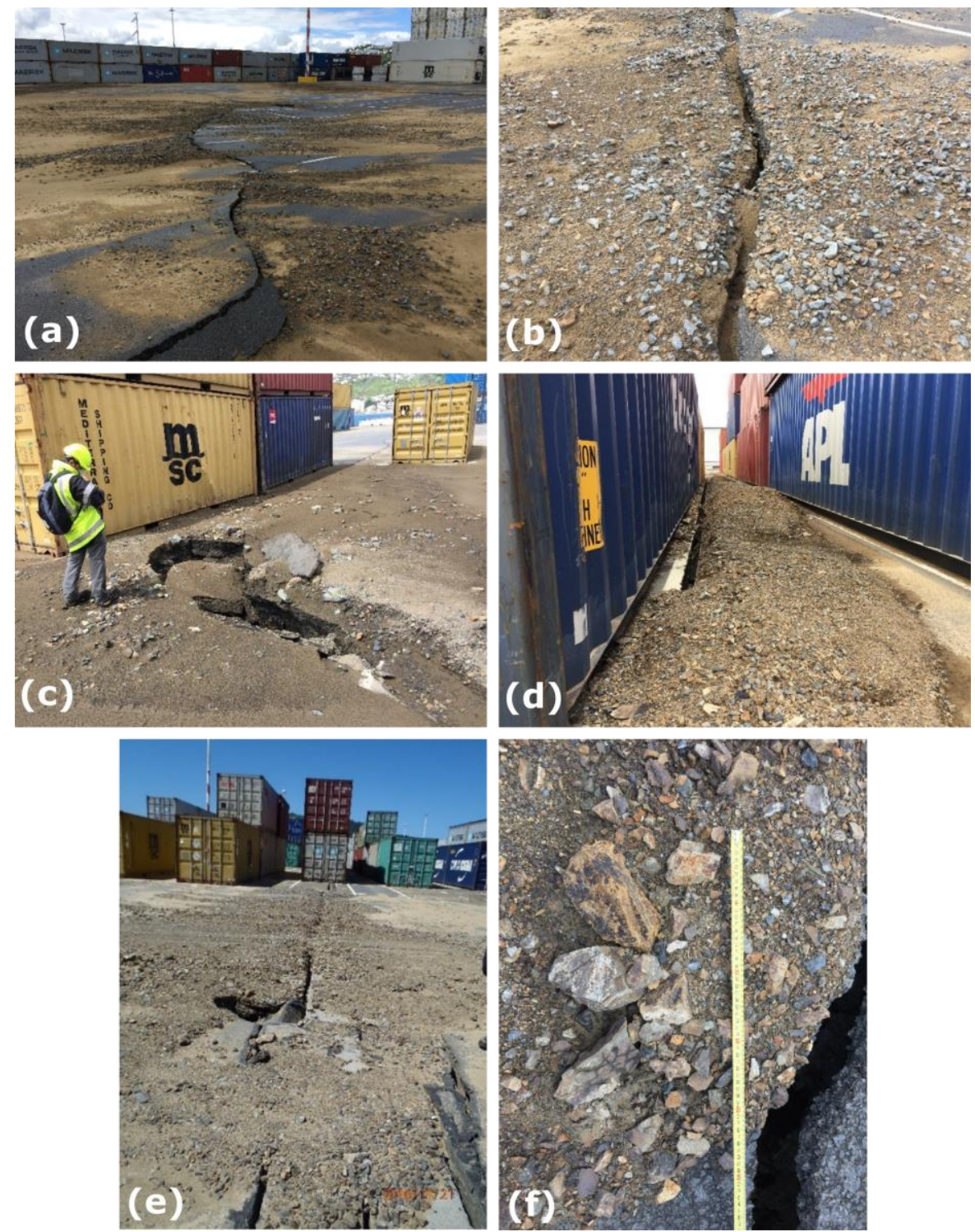

Figure 9: Gravelly ejecta at the Thorndon Container Terminal: (a) pavement cracking and ejected gravelly material (S41.280175 ${ }^{\circ}$ $\left.E 174.787308^{\circ}\right)$; (b) characteristic gravel-size fractions of the ejecta with some cobbles observed in this area $\left(S 41.280206^{\circ}\right.$ E174.787431 $1^{\circ}$ ); (c) larger amount of gravelly ejecta around a cavity and collapsed pavement surface (S41.280361

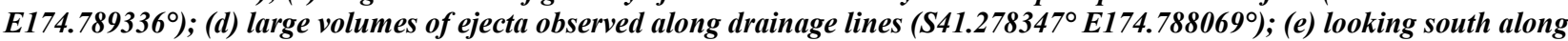

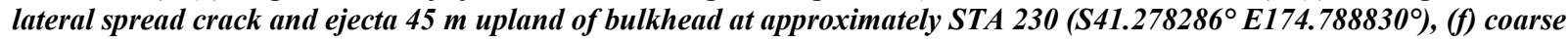
gravel and cobble ejecta $\left(S 41.280225^{\circ}\right.$ E174.787828 $)$. Photos taken on $17 N O V 16$ and 21 NOV16.
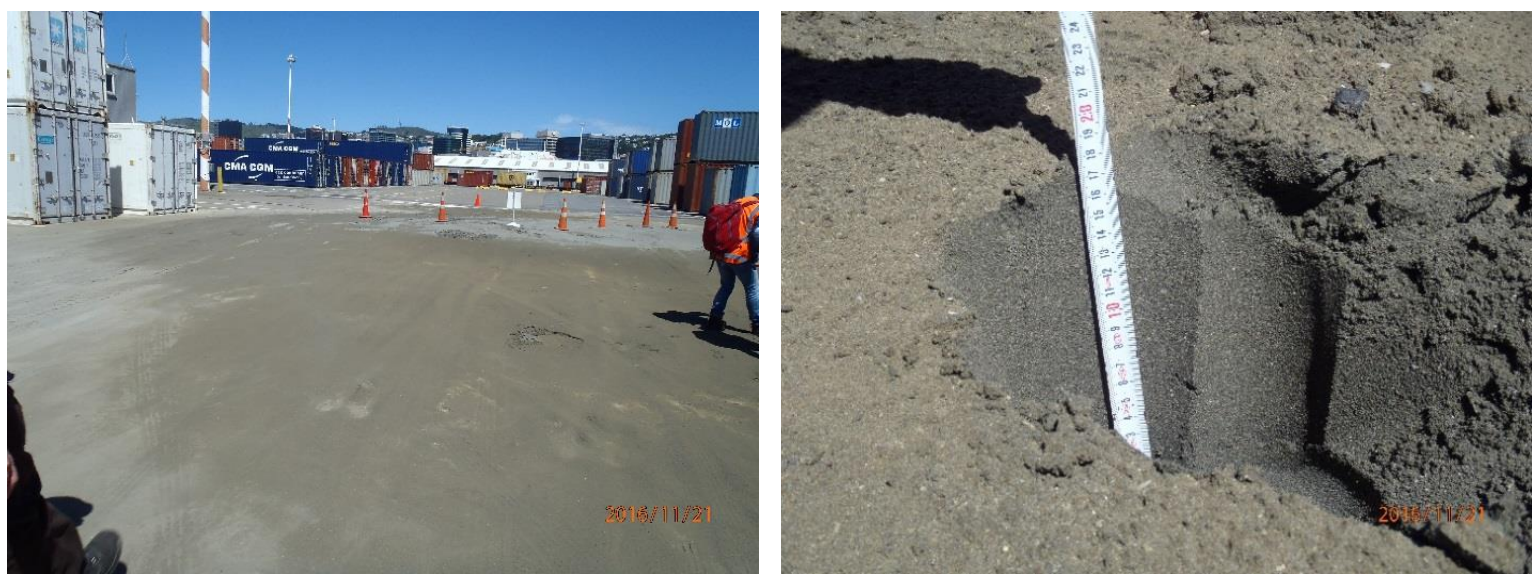

Figure 10: Sandy liquefaction ejecta with trace gravel among area of 1970 's end-dumped quarry rock reclamation (i.e., Thorndon Reclamation) at STA 145 and approximately $60 \mathrm{~m}$ west of the bulkhead. The ejecta deposit was approximately $170 \mathrm{~mm}$

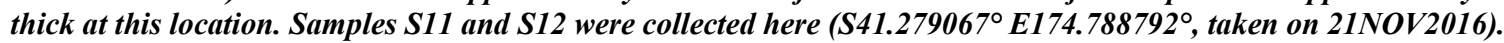




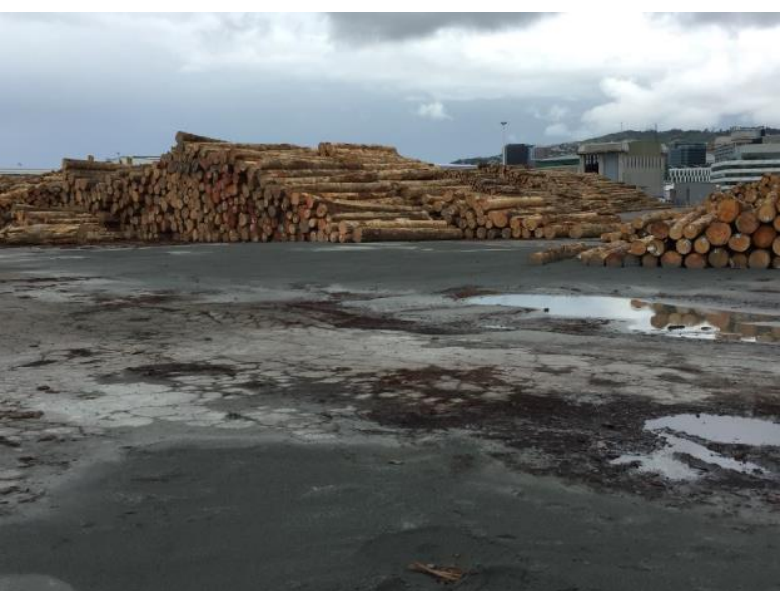

Figure 11: Sandy liquefaction ejecta in the log stacking area (hydraulic fill reclamation) in the northeast corner of CentrePort (Sample S13). (S41.274972 ${ }^{\circ}$ E174.788347 ${ }^{\circ}$, taken on 17 NOV16).

Grain size distribution curves for the 13 ejecta samples are shown in Figures $13 \mathrm{c}$ and $13 \mathrm{~d}$ where gravelly and sandy soils ejecta are shown, respectively. The shaded areas in the background of these figures show the range of grain size distributions for the reclamation fill and marine deposit samples (collected from subsurface explorations), which were shown previously in Figure 5. The grain-size curves of the gravel ejecta (solid lines in Figure 13c) are in good agreement with the grain-size distribution range of the gravelly soils of the Thorndon reclamation (shaded zone in Figure 13c). Similarly, the grain-size distribution curves of the sand ejecta (solid lines in Figure 13d) are generally consistent with those of the marine deposits, except that ejecta samples show more uniform grainsize composition. Note that the hydraulically-placed sandy fill was dredged from the original seabed; hence, it has the same composition as marine deposits. The grading of the ejected soils is also consistent with the sand fractions of the gravelly fill material. Samples from the ejected soils were also collected from 15 additional locations (shown in Figure 12) by Tonkin+Taylor on 14 November. Importantly, these samples were collected before the severe rainfall on 14-15 November [16] that potentially washed out some of the fines fractions from the ejected soils. Grain size distribution curves of the gravelly samples and sandy samples collected on 14 November are shown in Figures 13a and 13b in the same fashion as Figures $13 \mathrm{c}$ and $13 \mathrm{~d}$. By and large, both gravelly samples (solid lines in Figure 13a) and sandy samples (solid lines in Figure 13b) are in good agreement with the respective range of grain-size distribution curves obtained from borehole samples (shaded areas). Field visual classification of the collected ejecta samples is provided in [1].

\section{Settlement}

Differential hand-measured vertical settlement measurements are summarized in Figure 14. These measurements are of ground settlement relative to pile supported structures. Settlement of fill relative to buildings supported on a shallow foundation are excluded from this figure. The settlement of the fill south of the Old Seawall is generally in the range from 300 $\mathrm{mm}$ to $500 \mathrm{~mm}$, whereas settlement of the order of $100 \mathrm{~mm}$ to $200 \mathrm{~mm}$ was observed in the hydraulic fill north of the seawall. The largest settlement was observed at one location at the Thorndon Container Terminal just behind the wharf where a vertical offset of about $600 \mathrm{~mm}$ was observed. Approximately 180 meters inland of the Thorndon Wharf bulkhead, $180 \mathrm{~mm}$ of settlement were measured relative to what appeared to be the buried piles of the historic gantry crane (Figure 3).

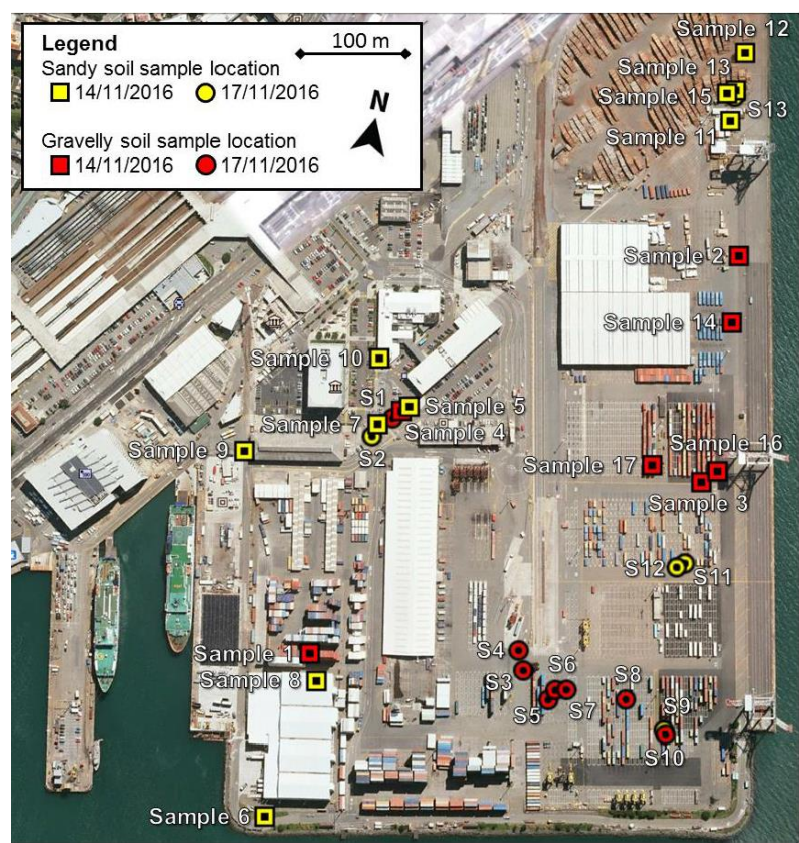

Figure 12: Location of liquefaction ejecta samples collected on 14 November (Sample 1 to Sample 17), and 17 November (S1 to S13). (base image from Google Earth ${ }^{T M}$ ).

\section{Lateral Spreading}

Lateral spreading generally was manifested by typical cracks and fissures on the pavement surface running perpendicular to the direction of spreading (or parallel to the waterfront). Characteristic spreading-induced movements are illustrated for the Thorndon Container Terminal (TCT) in this section, whereas additional observations on lateral spreading are discussed in the subsequent sections on wharves and buildings.

To quantify the magnitude and spatial distribution of lateral spreading at TCT, lateral displacement measurements were performed by ground surveying techniques $[17,18]$ along two transects in the east-west direction, denoted as TCW-1 and TCW-2 in Figure 15. Along each transect, ground cracks were identified and their location (horizontal distance from a reference point) and width were recorded. By summing up the crack widths one can estimate the size of lateral ground displacements as a function of the distance inland from the wharf, as illustrated in the plot at the top of Figure 15. Note that along TCW-2 two independent transects were performed approximately $10 \mathrm{~m}$ apart (in the N-S direction) to check the consistency in the ground displacement measurements. The cumulative opening of the cracks measured across TCW-1 and TCW-2 were 960 and $785 \mathrm{~mm}$, respectively, which indicates the edge of the fill moved laterally towards the sea (i.e., towards Thorndon Wharf) about $0.8 \mathrm{~m}$ to $1.0 \mathrm{~m}$, relative to the respective reference point of measurement. The lateral spreading was accompanied by a typical slumping mode of deformation involving lateral expansion and associated vertical settlement. Ground settlement relative to the wharf deck, at one location immediately inland of the bulkhead, was estimated to be $600 \mathrm{~mm}$, as indicated in Figure 15. The lateral movement measurements indicated with arrows in Figure 15 refer to the separation between the wharf bulkhead and the fill immediately inland of the bulkhead (i.e., the lateral seaward movement of the bulkhead relative to the adjacent ground), not the total (absolute) movement of the bulkhead. These measured relative displacements between the wharf and the backfill range from 200 to $500 \mathrm{~mm}$. 

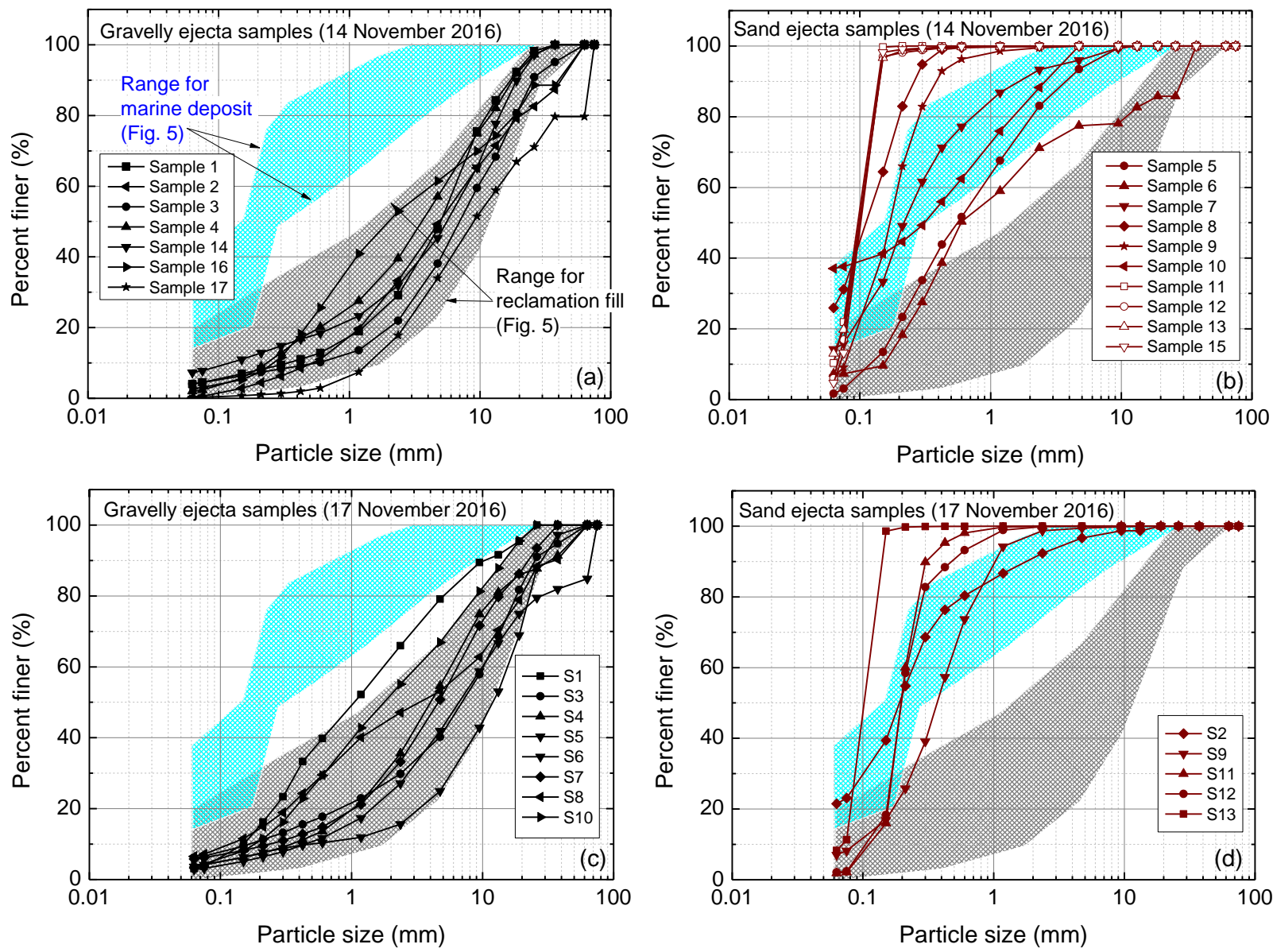

Figure 13: Grain size distribution for liquefaction ejecta samples collected on reclaimed land from (a) gravelly quarry rock fill on 14 November, and (b) sandy fill on 14 November, (c) gravelly quarry rock fill on 17 November, and (d) sandy fill on 17 November. Shaded regions show ranges of grain size for marine deposits and reclamation fill collected from subsurface explorations (plotted in Figure 5).

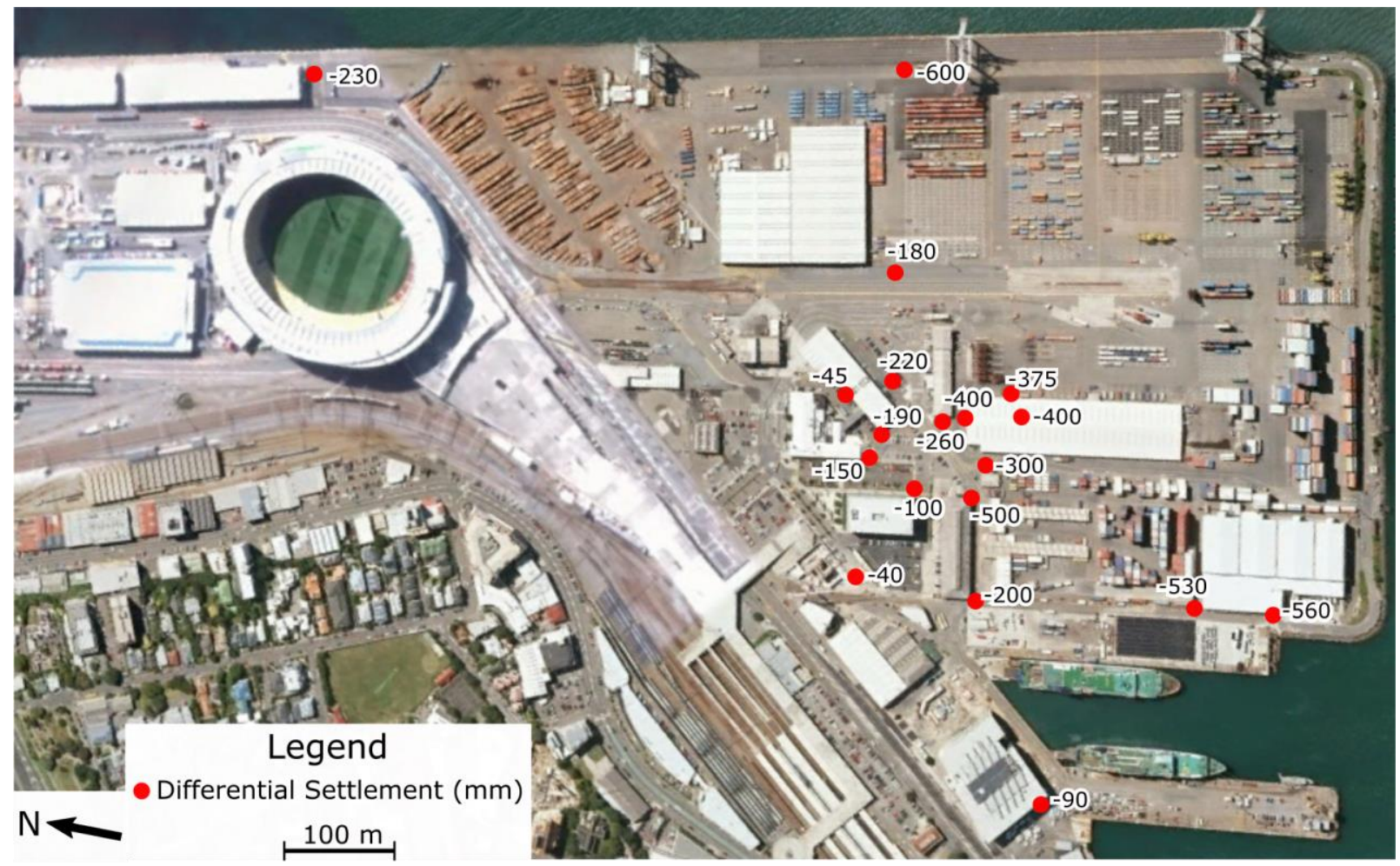

Figure 14: Location and magnitude of differential settlement measurements obtained during inspections. All values are in mm, and represent settlement of the ground surface relative to a pile supported structure (Base image from Google Earth ${ }^{T M}$ ). 

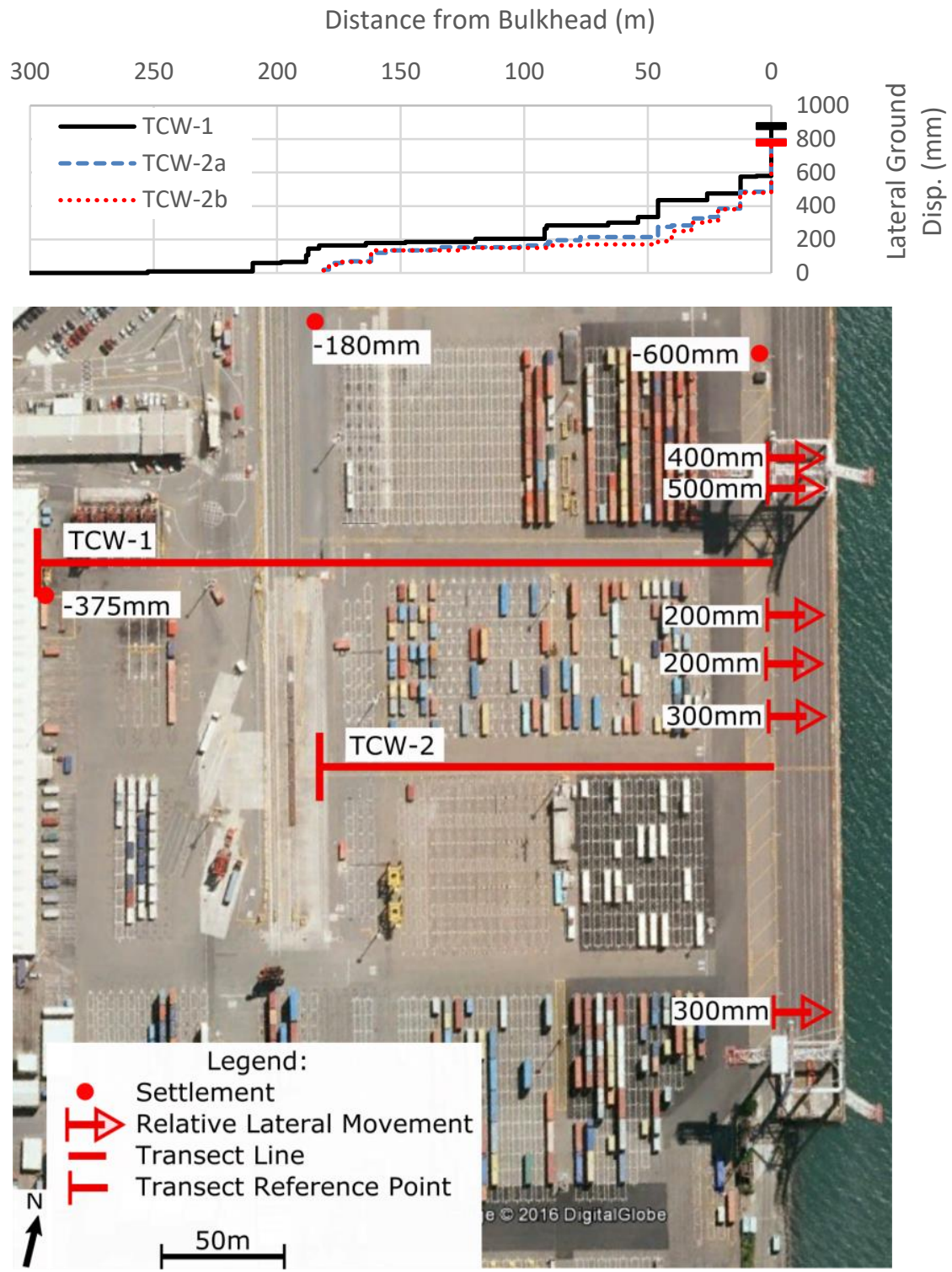

Figure 15: Location of west-to-east transects for lateral spreading measurements towards Thorndon Wharf during inspections. Plots at the top show cumulative lateral ground displacement versus horizontal distance from the bulkhead (Base image from Google Earth ${ }^{T M}$ ).

\section{LIDAR FIELD SURVEY}

Ground-based LiDAR surveys were completed at CentrePort from 28 November to 1 December 2016 to document the ground and structural performance during the 2016 Kaikoura earthquake. The LiDAR surveys were collected to supplement and validate structure from motion (SfM) point clouds from recent unmanned aerial vehicle (UAV) surveys.

The surveys were completed using a Leica P40 terrestrial laser scanner with a Leica GS14 GNSS receiver mounted above at a calibrated offset of $0.1580 \mathrm{~m}$. Scans were spaced generally at 30-40 $\mathrm{m}$ apart along transects (Figure 16); however, the spacing varies substantially to accommodate visibility constraints as well as safety considerations since the port was operational during the surveys. Scans were completed for a 360 degree panoramic view. Most scans also have co-acquired, high resolution imagery utilizing the internal calibrated camera in the Leica P40 scanner. At each location where imagery were collected, the camera captured over 270 (1920x1920) images for the full dome, which were mosaicked and blended together to map colours to the point cloud. For some of the indoor scans with poor lighting conditions or where scans needed to be completed rapidly, the camera imagery was not acquired. For indoor scans, the GNSS receiver and handle were removed prior to scanning, in most cases, for full overhead scanning. A local Continually Operating Reference Station (CORS) WGTT was utilized as the base station. Details on the LiDAR surveying including GNSS processing, registration, and DEM creation are provided in [1].

Figure 17 shows a cross-section (LT1) extracted from the LiDAR data that was obtained on the west edge of the road immediately west of Building S37. The peaks in this plot indicate locations of the buried piles whereas the lower portions show the magnitude of settlement of the pavement surface around those piles. In absence of detailed survey data prior to the event, the original surface was estimated by fitting a $3^{\text {rd }}$ order polynomial $\left(\mathrm{R}^{2}=0.99\right)$ to the tops of piles showing higher elevations in the local area. Using this assumption, a differential settlement of the ground (settlement of the ground relative to the ground surface covering the tops of the piles) in this area was estimated to be on the order of $200 \mathrm{~mm}$ to $300 \mathrm{~mm}$. LiDAR surveying data on the performance of wharves and buildings are presented in the subsequent sections. 


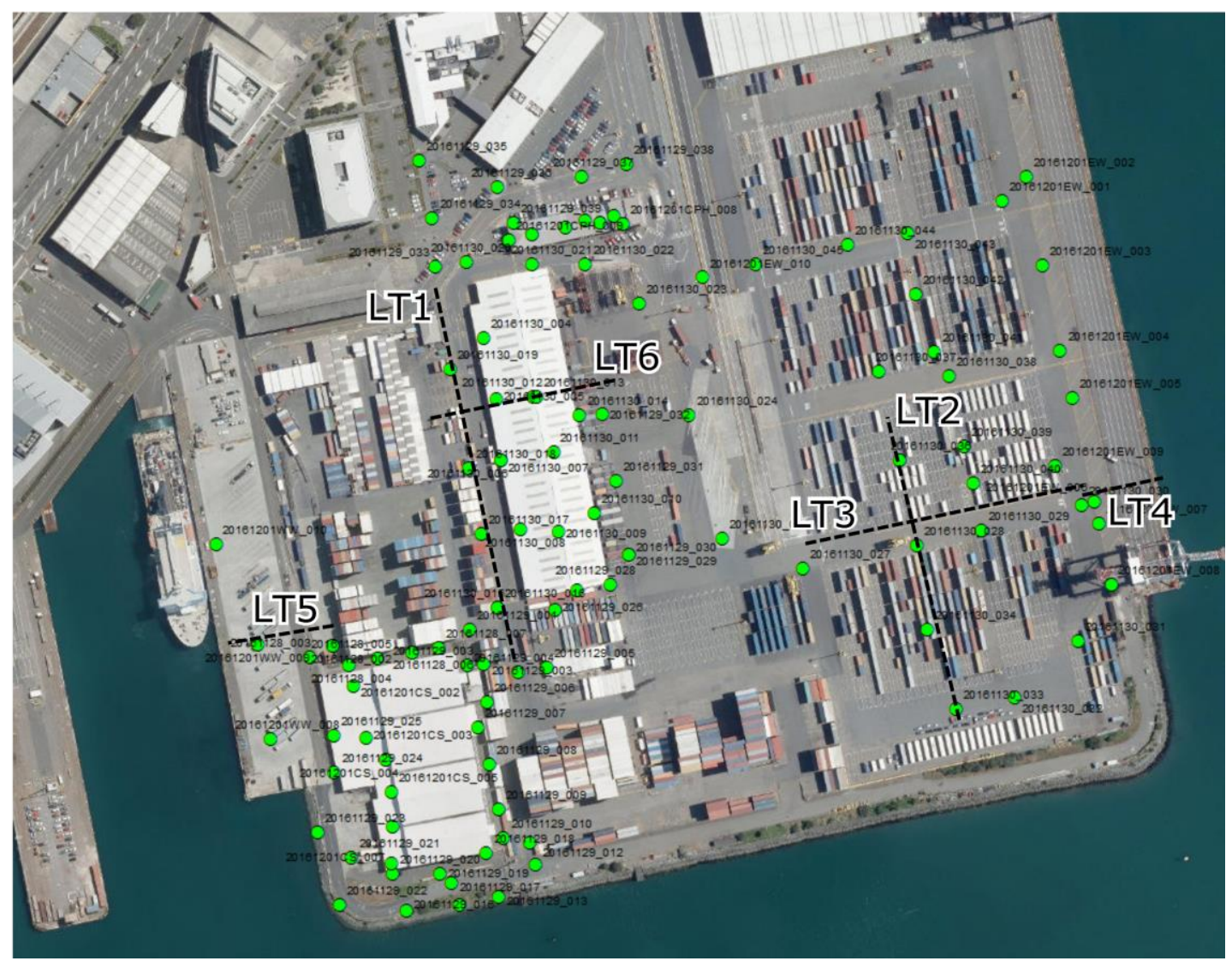

Figure 16: Locations (green circles) where ground-based LiDAR scans were obtained at the CentrePort. Additional scans were captured inside the Cruise Ship Terminal to the North that are not shown. Transects from the LiDAR data shown later in the report are identified. Note that the basemap is from ESRI prior to the earthquake.

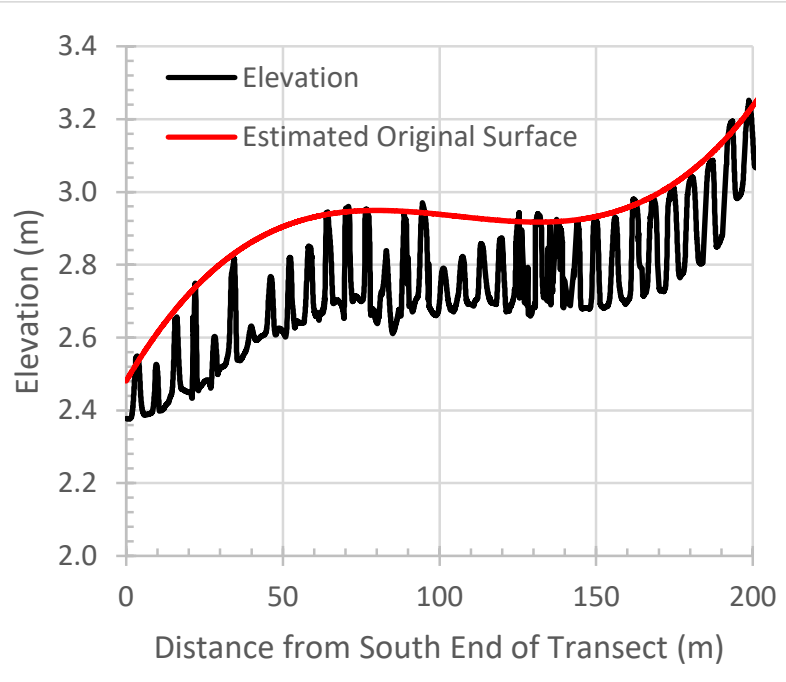

Figure 17: Post-earthquake elevations for transect (LT1) along west side of roadway west of $S 37$; the red line represents the estimated pre-elevation surface.

\section{EFFECTS ON WHARVES}

CentrePort Wellington has two wharves: Thorndon Container Wharf and King's Wharf (see Figure 18). The port's primary container operation takes place on Thorndon Container Wharf, which is on the eastern side of the port. King's Wharf, which is on the western side of the port, supports primarily roll-on/rolloff cargo.

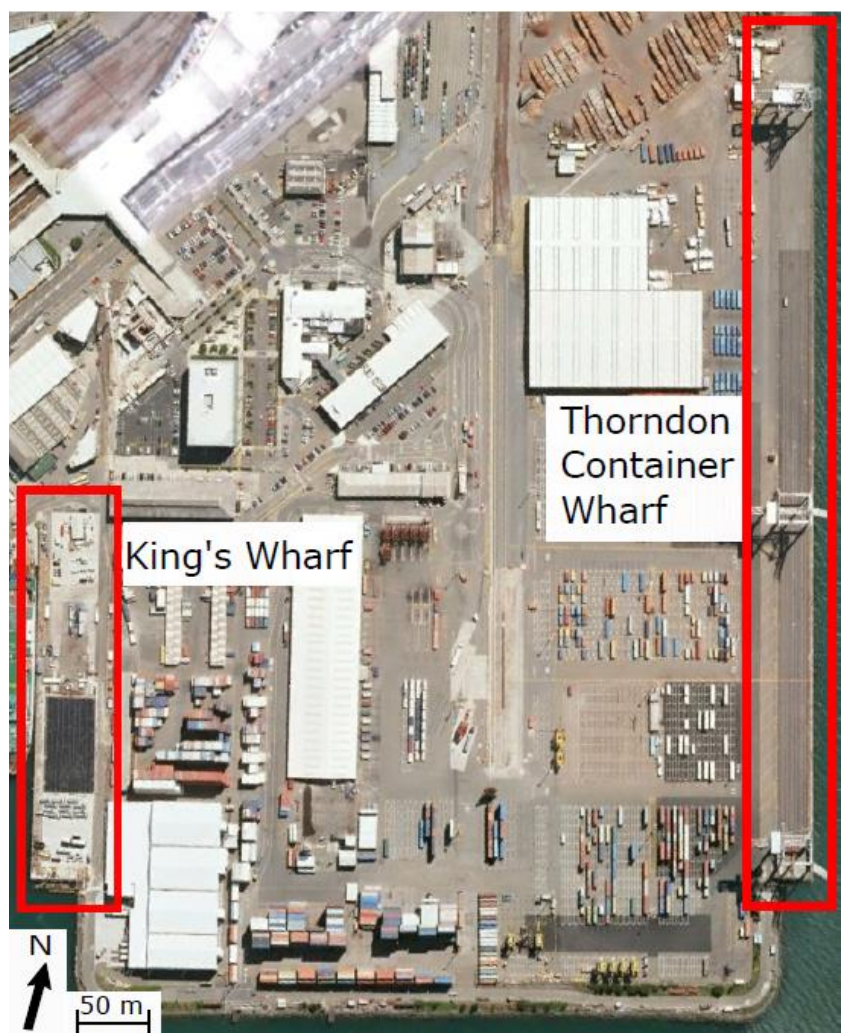

Figure 18: Aerial photograph highlighting the locations of the Thorndon Container and King's wharves of CentrePort Wellington (Base image from Google Earth ${ }^{T M}$ ). 


\section{Thorndon Container Wharf}

The Thorndon Container Wharf is supported on seven rows of 508x508-mm square, pre-stressed concrete piles. Pile bents are spaced $3.66 \mathrm{~m}$ on center (approximately $\mathrm{s}=6 \mathrm{~B}$ ). The piles are generally $18 \mathrm{~m}$ long under the eastern crane rail and 20 to $23 \mathrm{~m}$ long (increasing in length to the south) under the western crane rail [4].

As described previously, widespread liquefaction of the Thorndon Reclamation was accompanied with settlement of the fill and lateral spreading towards Thorndon Wharf. Ground survey measurements indicate that the lateral spreading displacements at the edge of the fill (bulkhead) reached about $0.8 \mathrm{~m}$ to $1.0 \mathrm{~m}$, relative to the respective reference points Cardno performed an aerial unmanned aircraft systems (UAS) survey of the port that captured vertical settlement and lateral movement (Figure 19). The magnitude of lateral spreading displacement and ground settlement from the UAS survey are generally consistent with those measured by the QuakeCoREGEER team [1]

The lateral thrust from the displaced fill pushed the inland piles of the wharf towards the sea, causing tilt of the wharf. The crane rail tilted $2.5^{\circ}$ down towards the sea at TWC -1 and $1^{\circ}$ down towards the sea at TWC-2 (see Figure 15 for transect locations). Lateral seaward movement measurements of the bulkhead relative to the ground immediately inland range from 200 to 500 $\mathrm{mm}$. These estimates are based on surface observations of asphalt cover movement, which do not necessarily represent movement of the underlying soil beneath the asphalt. In fact, at this interface zone of large horizontal and vertical offsets between the fill and wharf, cavities were apparent immediately below the distorted asphalt cover. Figure 20 shows the vertical offset created between the pile-supported wharf and reclaimed fill behind the wharf. Deformation of the Thorndon Wharf was also captured in the LiDAR survey (see Figure 21).

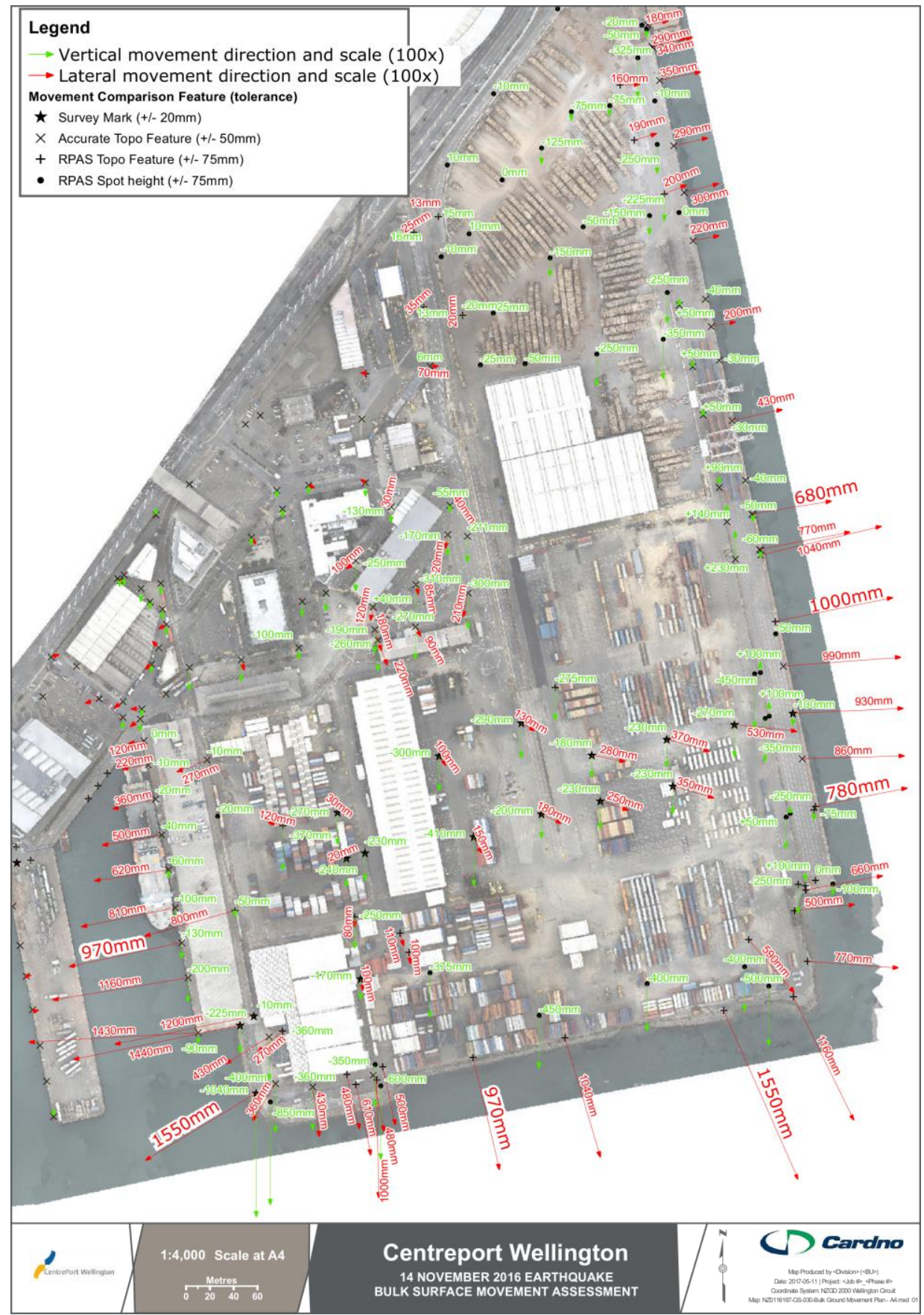

Figure 19: Displacements measured from an aerial UAS survey of Thorndon Reclamation and Wharf (performed by Cardno). 

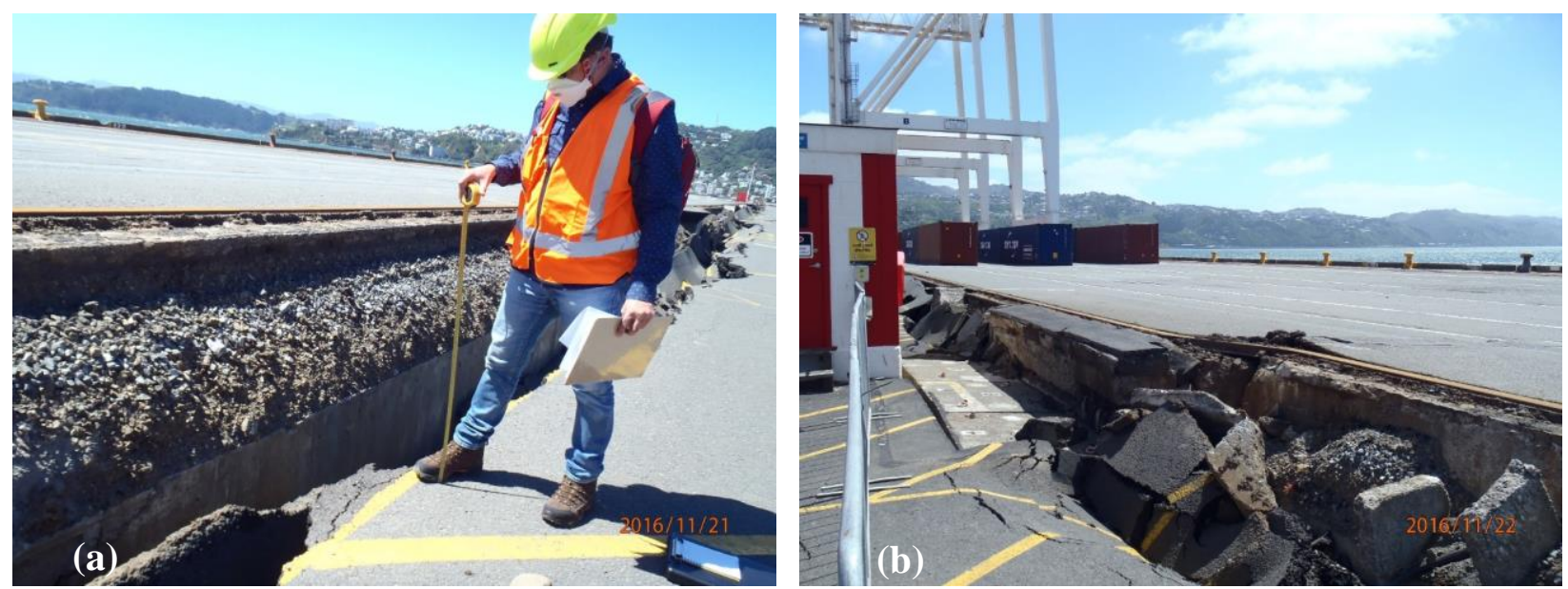

Figure 20: (a) Looking south along Thorndon Wharf bulkhead at approximately STA 240. Approximately 600 mm of ground settlement was measured relative to pile-supported wharf. (S41.278250 E174.789205 ${ }^{\circ}$, taken at 1124 hrs on $\left.21 N O V 16\right)$; and (b)

Looking north along Thorndon Wharf bulkhead at approximately STA 280. Approximately 600 mm of ground settlement was measured relative to pile-supported wharf. (S41.277743 ${ }^{\circ} \mathrm{E174.} 789236^{\circ}$, taken on $\left.22 \mathrm{NOV16}\right)$.

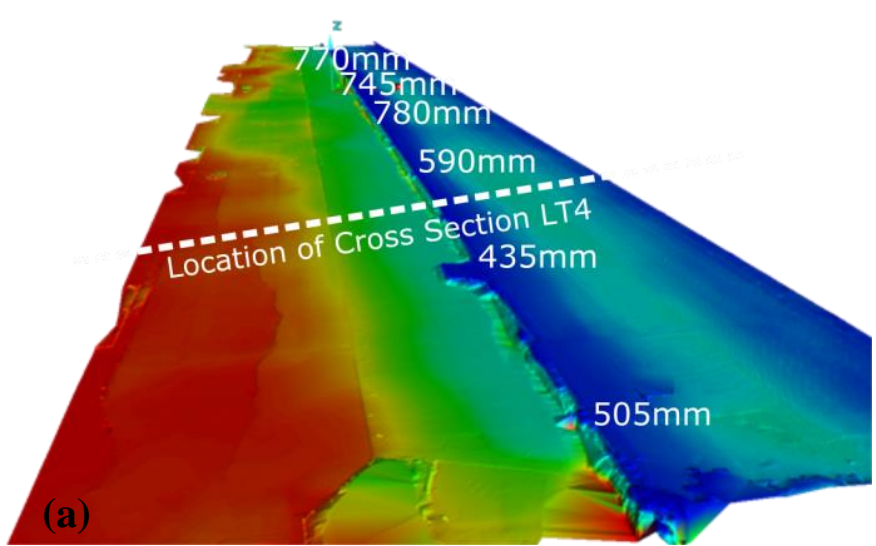

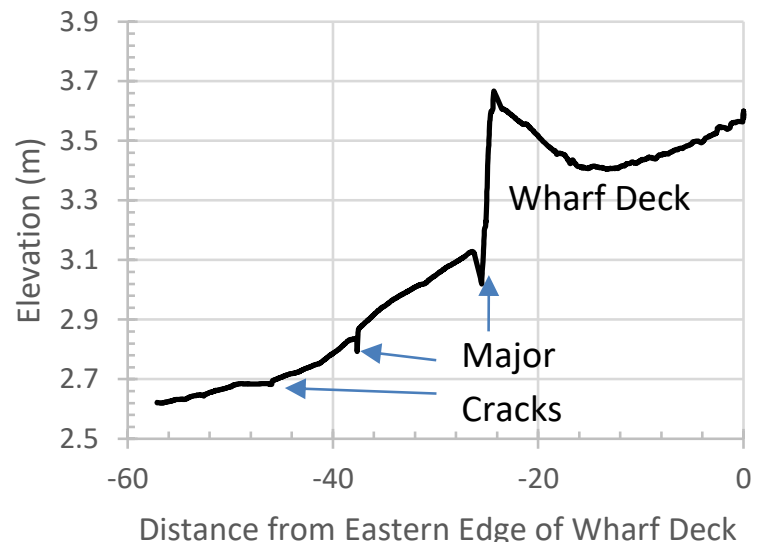

(b) (m)

Figure 21: (a) Perspective view of the LiDAR DEM of the eastern section of the port looking northward including the Thorndon Wharf and surrounding fill area coloured by elevation to highlight discontinuities from cracks. Elevation ranges from approximately $2.60 \mathrm{~m}$ (red) to $3.60 \mathrm{~m}$ (dark blue). Differential settlements between the wharf and reclaimed land are identified. (b) Elevation profile for cross section LT4 across Thorndon Wharf and inland fill.

The QuakeCoRE-GEER team was informed that concrete piles had been sheared near the pile cap (from a boat survey by others; T+T (2016) private communication). From the south side of the port, the team did observe a vertical bulkhead pile sheared just below the pile cap.

\section{King's Wharf}

King's Wharf is supported on driven timber piles. The fill behind the wharf liquefied and moved laterally towards the wharf displacing King's Wharf seaward (to the west). Spreading displacements were largest at the south end of the wharf where the lateral soil movement exceeded $1.1 \mathrm{~m}$, based on ground surveying measurements. The ground along the edge of the reclamation displaced westward (towards the wharf) and collapsed downwards (beneath the wharf deck). The ground settlement relative to the deck of the wharf was measured with hand surveys to be approximately $560 \mathrm{~mm}$ at the southeast corner of the wharf and $530 \mathrm{~mm}$ at the northwest corner of the CS building, which is described later.
Westward movement of the structure is visible in Figure 22a, in which the southern bent of piles leans to the west. The inland timber piles split due to seaward lateral movement of the deck relative to this row of piles (Fig. 22b). Vertical warping of the wharf deck is shown in the LiDAR DEM (Fig. 23a). The wharf deck exhibits significant concavity (downward) as observed in the cross section plotted on Figure 23b. Differential settlement between the wharf and adjacent ground range from $475 \mathrm{~mm}$ to $630 \mathrm{~mm}$, as measured from the LiDAR-derived DEM.

\section{EFFECTS ON BUILDINGS}

\section{General}

Several engineered buildings located on or adjacent to CentrePort were affected by the liquefaction-induced ground movements at the port. Most buildings were supported on pile foundations. A few buildings were supported on shallow foundations. Observations for each building identified in Figure 24 are presented in the following sections. 

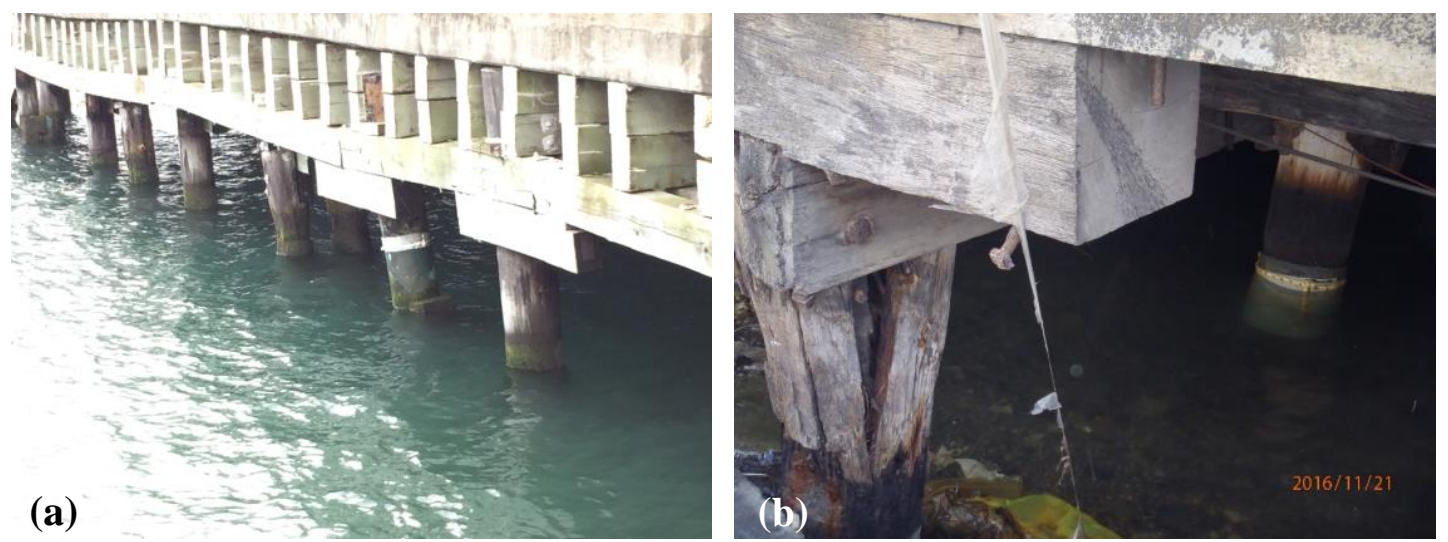

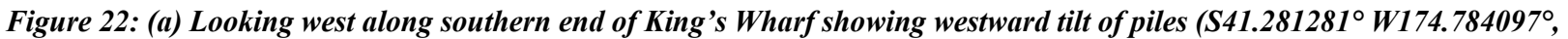
taken on 17NOV16), and (b) looking under King's Wharf at an inland bulkhead pile; timber pile is split from lateral movement of the deck relative to the pile. $\left(S 41.280900^{\circ} \mathrm{E} 174.784375^{\circ}\right.$, taken on $\left.21 \mathrm{NOV16}\right)$.
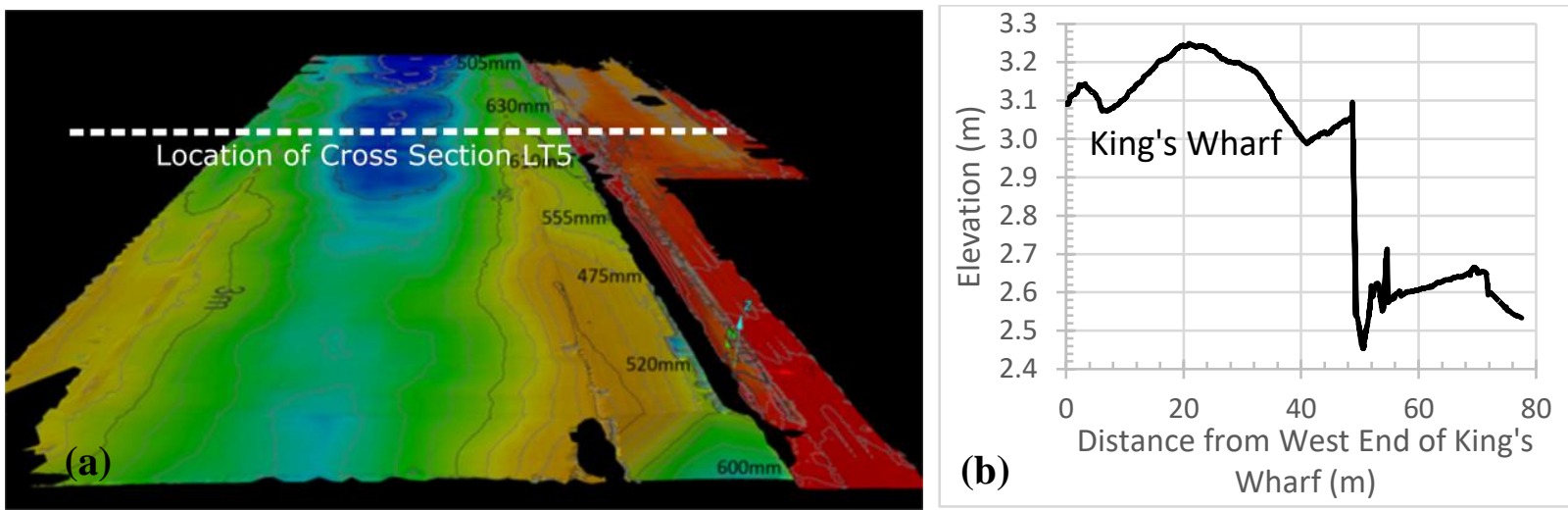

Figure 23: (a) LiDAR derived DEM (looking northward) of the pile-supported King's Wharf showing measurements of differential settlement between the wharf and the adjacent ground. Elevation ranges from approximately $2.50 \mathrm{~m}$ (red) to $3.30 \mathrm{~m}$ (dark blue). (b) Cross section LT5 taken across King's Wharf and the adjacent ground.

Buildings on Shallow Foundations

\section{CPH Building}

The CPH building (S41.27829 ${ }^{\circ}$ E174.78618 ${ }^{\circ}$, see Figure 24$)$ is founded on reinforced concrete (RC) spread footings connected with RC grade beams (Figure 25a). There were no apparent signs of structural distress, and the building was operational at the time of the reconnaissance in late November 2016. The building and immediately surrounding fill settled relatively uniformly. Settlement appeared to be more or less uniform across the building footprint, as there were no apparent signs of relative movement or tilt of the ground floor of the $\mathrm{CPH}$ building from the visual investigation. However, a preliminary analysis of the LiDAR scans indicate a slight tilt (i.e., of 0.105 degrees) in the large operations room on the east end of the building. Ground a few meters to the west of the CPH building did not appear to settle significantly, because it was supported by the buried precast seawall that ran along the bulkhead of the partially demolished Pipitea Wharf, which minimized liquefaction-induced settlement of the ground above it. The building and fill settled approximately 230 to $260 \mathrm{~mm}$ relative to the elevated ground supported on the seawall (Figure 25b).

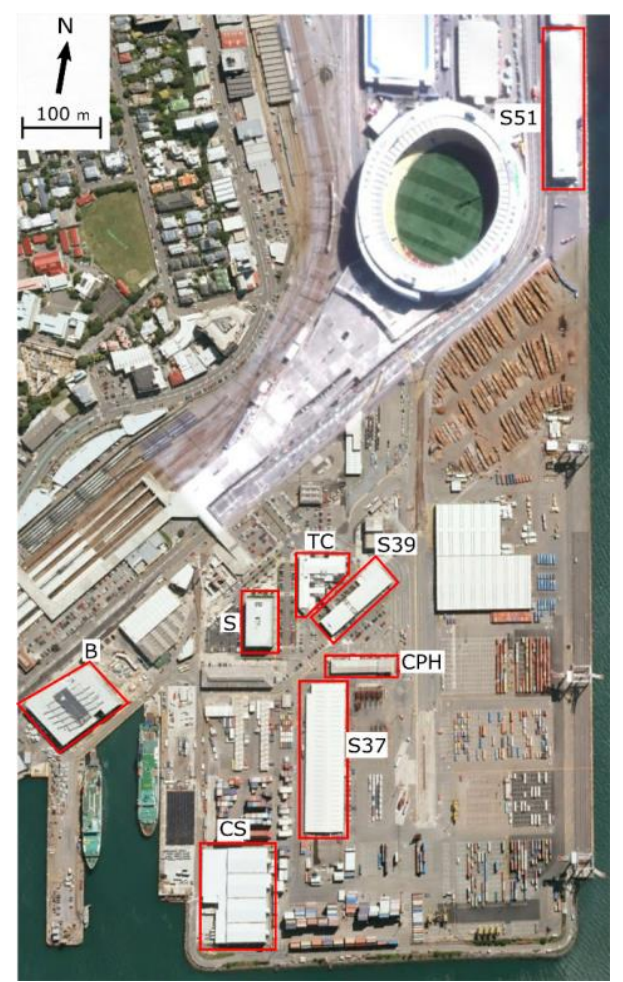

Figure 24: CentrePort Wellington map showing buildings surveyed (Base image from Google Earth ${ }^{T M}$ ). 

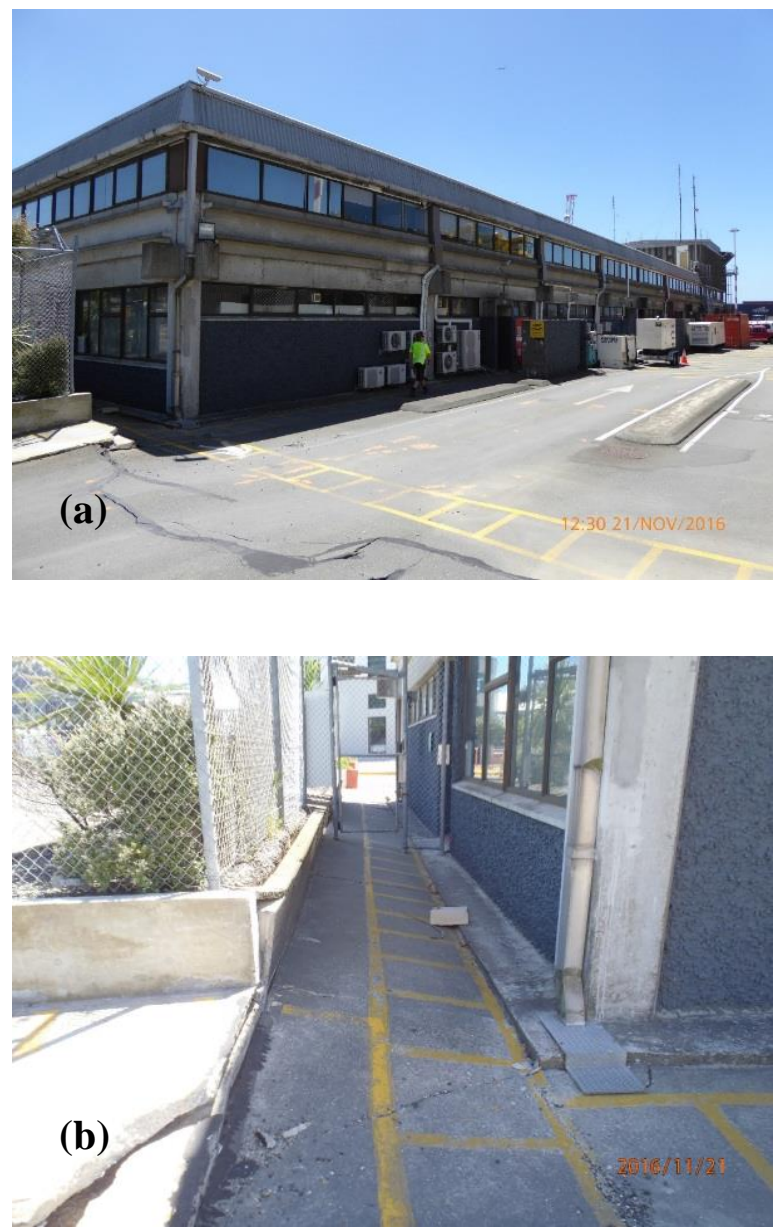

Figure 25: (a) Uniform settlement of CPH building which is founded on shallow foundations that apparently displaced downward the same amount as the surrounding fill. This photo is looking northeast at the southwest corner of the

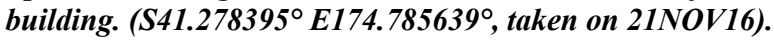
(b) Uniform settlement $(230-260 \mathrm{~mm})$ of the building relative to ground supported on the buried precast seawall that ran parallel to the bulkhead of partially demolished Pipitea Wharf. Looking north along western wall of $\mathrm{CPH}$ building. The perimeter walkway slopes down towards the building at 11 degrees over 1.35 meters. $\left(S 41.278395^{\circ} \mathrm{E} 174.785639^{\circ}\right.$, taken on 22NOV16).

\section{CS Building}

The CS building ( $\mathrm{S} 41.28105^{\circ} \mathrm{E} 174.78483^{\circ}$, see Figure 24 ) is supported on a composite shallow foundation with RC spread footings and mats. The building consists of an irregular-shaped single-story open loading bay in its western part (herein called the Shed) and a rectangular-shaped large cold storage facility on its eastern part (herein called the Freezers). The structural frames and supporting foundations of these two parts of the building appear to be independent. From observation, the structural system of the Shed is composed of concentricallybraced steel frames. The QuakeCoRE-GEER team members were given access to the Shed and the ground around the building, but not to the Freezers. The differential ground movements across the building footprint induced structural deformation in the CS building. Seaward lateral ground movements on the order of $1 \mathrm{~m}$ occurred towards the western and southern slopes in the southwest corner of the CentrePort reclaimed land.

Figure 26 shows the location of six transects along which the location and width of lateral ground cracks in the pavement surrounding the CS building were recorded. Superimposed on this figure are plots of cumulative lateral ground displacement as a function of distance from the crest of the waterfront slopes for each transect. They show the fill moved towards the sea (southward) approximately 0.8 to $1.3 \mathrm{~m}$ (relative to the reference point of measurement), at the south side of the building. The fill moved 0.8 to $1.1 \mathrm{~m}$ to the west. The foundations of the building were subjected to a lateral stretch of approximately $200 \mathrm{~mm}$ over a column span of approximately $8.8 \mathrm{~m}$. This corresponds to a lateral strain of about $2.3 \%$.

Gravelly liquefaction ejecta was observed around the building. Figure 27a shows lateral ground movements and partial collapse of the slope at the reclamation edge along the western wall of the Shed of the CS building (which is parallel and adjacent to King's Wharf), where the ground settled approximately $530 \mathrm{~mm}$ relative to the King's Wharf. This part of the building is closest to the crest of the slope and it underwent the largest lateral movement. Figure 27b shows lateral movements near the crest of the western slope, and Figure 27c shows lateral spreading towards the southern slope with a consequent vertical offset of approximately $1.1 \mathrm{~m}$. Significant separation between the CS building foundation and external pavement slab were observed on the south side of the building (as well as settlement and spreading of the surrounding pavement). Shallow soils beneath the pavement were exposed in large cracks and vertical offsets surrounding the building, and these soils consist of gravelly quarry-rock reclamation fill.

Figure 28a documents significant cracking resulting in exposure of rebar in the foundation of the CS building along the exterior northern wall. The photograph looks south at the north wall of the CS building, however, this same ground crack runs northward continuously for approximately $100 \mathrm{~m}$. Crack widths and locations along the bottom of the outside walls of the CS building were also measured. Figure 29 shows results of this survey, which are consistent with the previously described lateral spreading measurements and also indicate a lateral stretch of the shallow foundation of the Shed of approximately $200 \mathrm{~mm}$ in the westward direction along the northern wall.

The western part of the CS building (i.e., the Shed) is a steelframe, single-story structure with an open bay. The total span of the Shed on its north end is about twice as wide as its span width on its south end. The northwest part of the Shed is closest to the free-face of the slope and consequently experienced the largest lateral ground movement. Thus, the northern part of the Shed displaced laterally westward more than its southern end. The westward lateral movement of the north end of the building separated the Shed from the Freezers along the northern half of the building (Figure 28b). The differential lateral ground movements across the north-south length of the Shed produced deformations, cracks, and openings in the overlying foundation and structure. This deformation pattern was apparent by comparing the magnitude of building cracks along the north wall to those on the south wall (Figure 29), as well as separation of construction joints in the interior floating slab of the Shed. Measurements of construction joint separation in the slab are shown schematically in Figures 30 for the southern part of the Shed. The differential lateral ground movements across the footprint of the Shed part of the CS building were also manifested in the deformation pattern of its steel framing. This deformation pattern is shown in Figure 31, which is a schematic of the three west-most columns of the four column frame along the north wall looking north from the interior. The column span is approximately $8.7 \mathrm{~m}$. In addition to the tilting of these columns along the north wall, at least two columns along the east wall of the shed were rotated at the base, causing buckling of the concentric bracing between columns (Figure 32). 

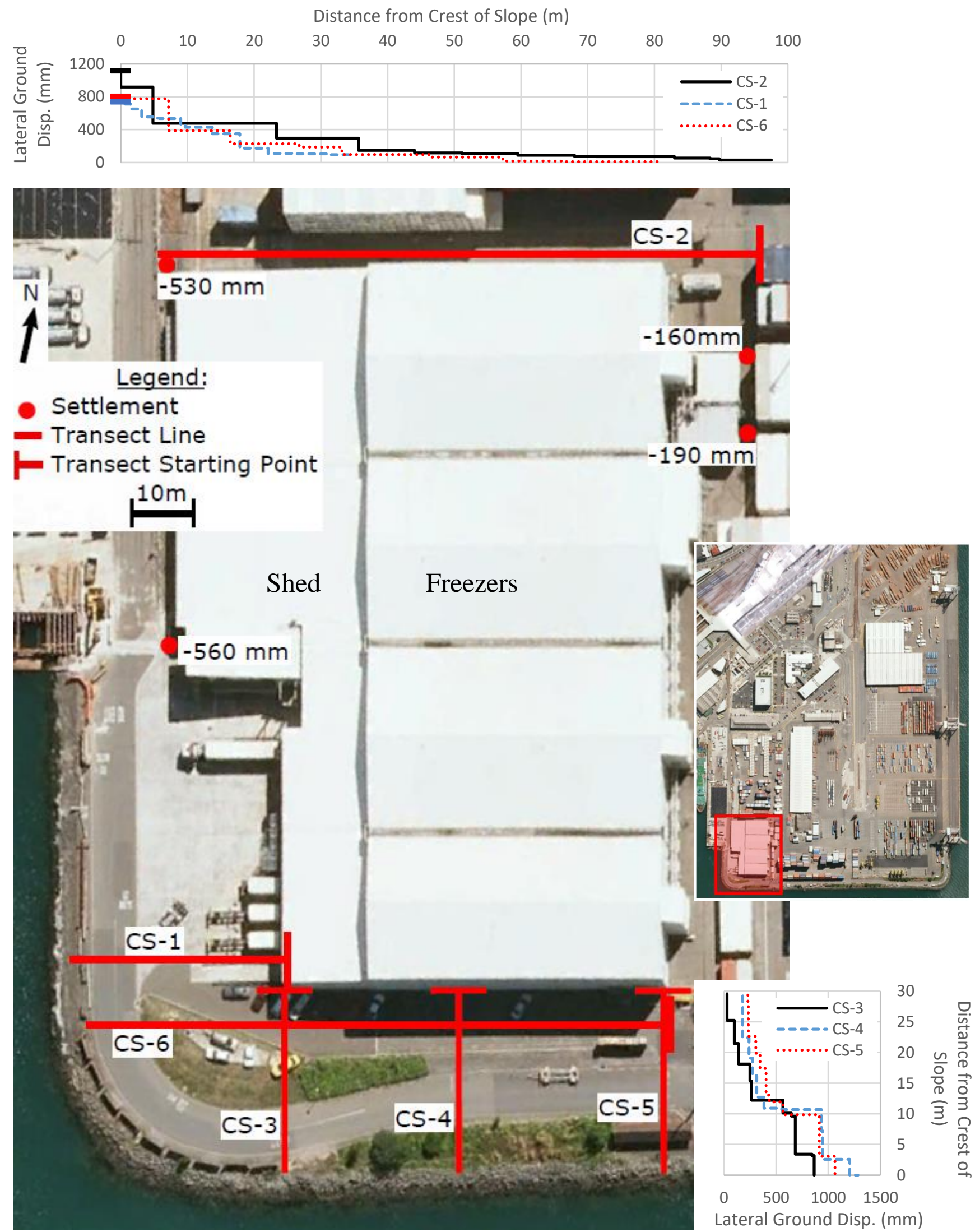

Figure 26: CS building lateral ground movement transects and vertical settlement measurement locations. Cumulative ground displacement versus distance from crest of slope are provided in the inset plots. Note that the crest of slope is further east at CS-2 than at CS-1 and CS-6, therefore, displacement plots do not perfectly align with satellite image for CS-2. Settlement measurements to the northeast are relative to the building which also settled. 

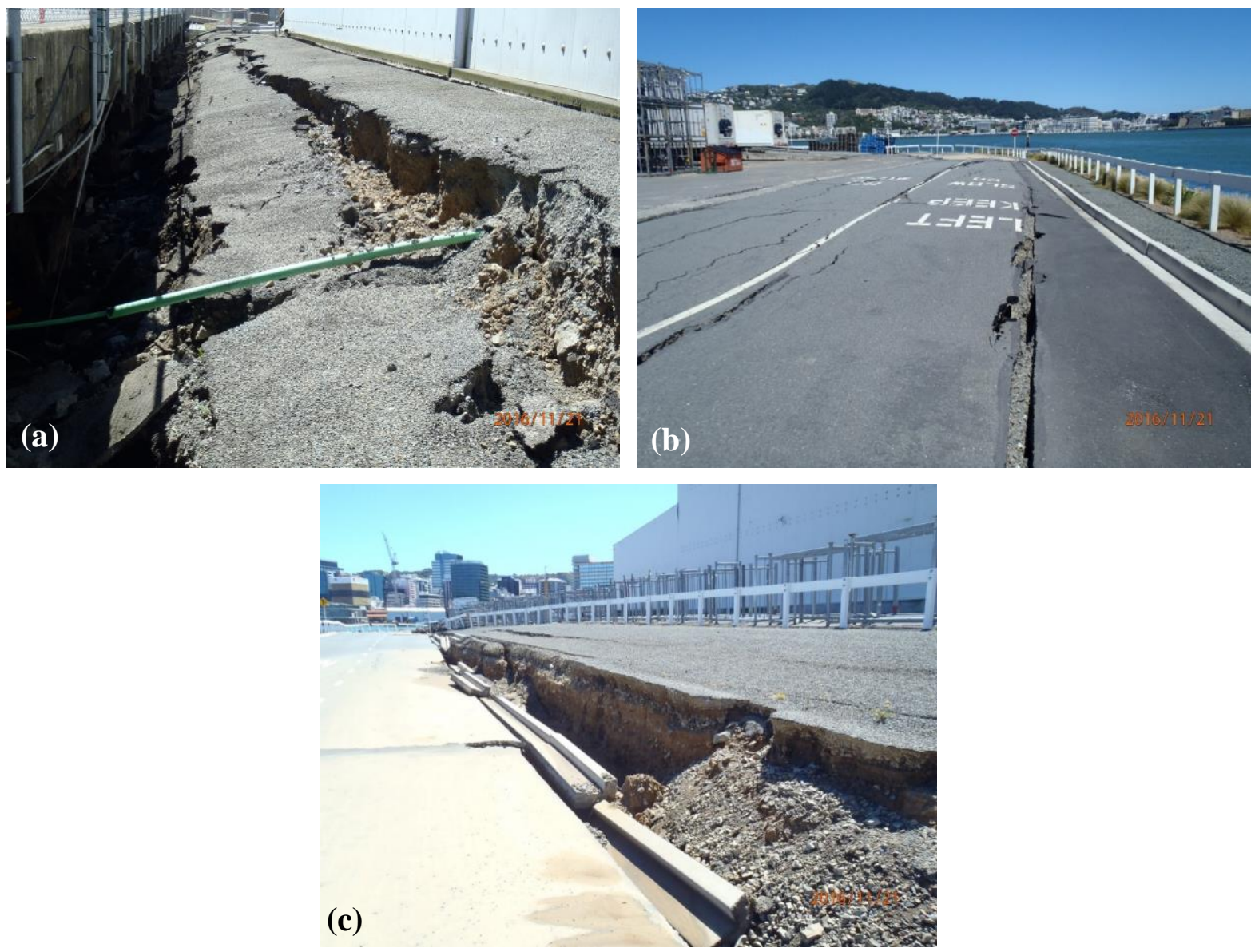

Figure 27: (a) Looking north along the west wall of the CS building. The ground settled approximately 530 mm relative to the pile-supported bulkhead of King's Wharf, which is shown at the left side of the photograph. $\left(S 41.280923^{\circ} \mathrm{E}^{2} 74.784389^{\circ}\right.$,

21NOV16); (b) Ground cracks in area west of the CS building and along the southwestern slopes of CentrePort (looking south). The CS building can be partially seen on the upper left corner of the photograph. $\left(S 41.281478^{\circ} \mathrm{E}^{2} 74.784430^{\circ}, 21 \mathrm{NOV16}\right)$; and (c) Approximately $1.1 \mathrm{~m}$ of vertical offset resulting from the southward lateral movement of the southern edge of CentrePort reclaimed land near its western side. Looking west near the southern wall of the CS building. $\left(S 41.281701^{\circ} \mathrm{E174.785268}^{\circ}\right.$, 21NOV16).
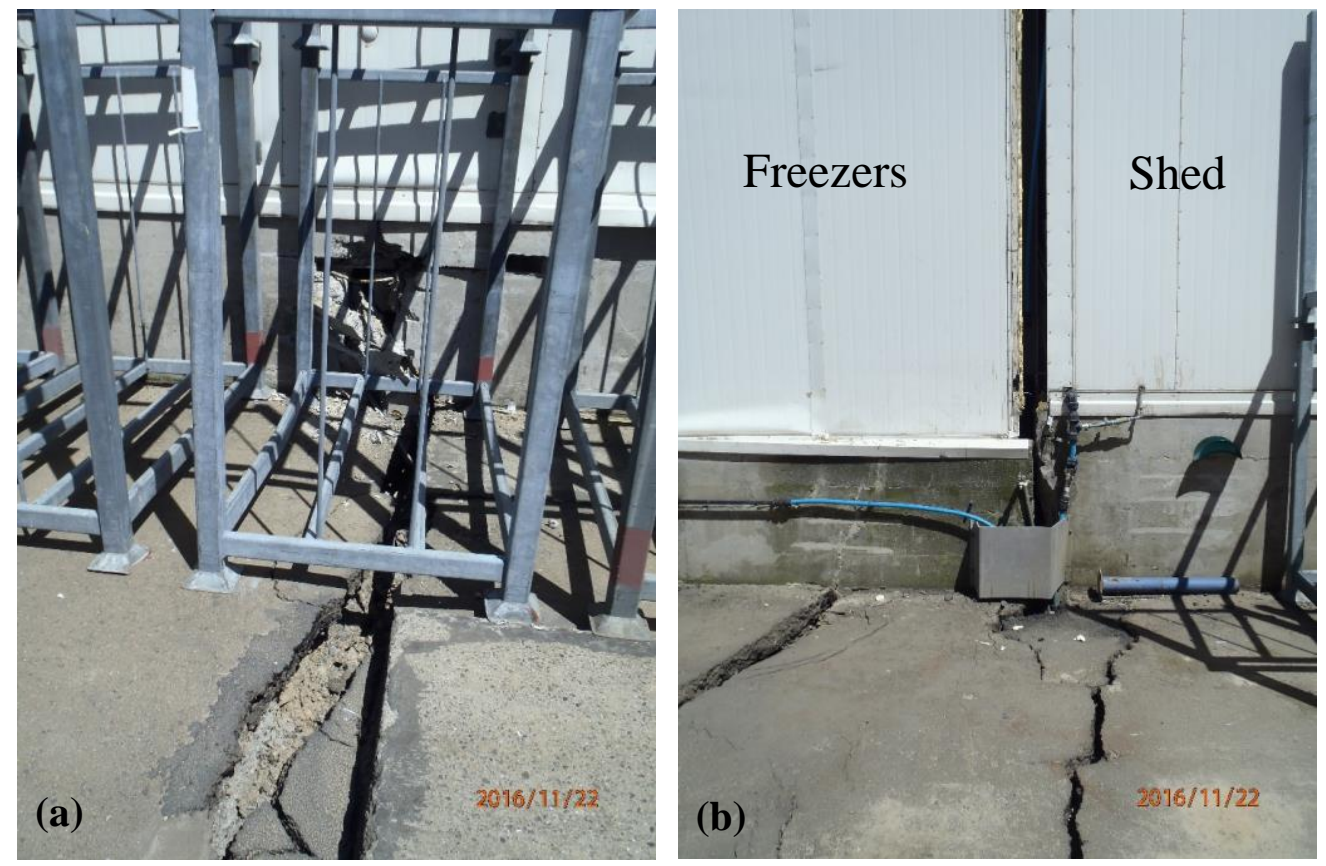

Figure 28: Cracks along the exterior north wall of CS building: (a) $180 \mathrm{~mm}$ crack in the foundation of the CS shed from westward lateral spreading $\left(S 41.280607^{\circ} \mathrm{E} 174.784533^{\circ}, 22 \mathrm{NOV16}\right)$, and (b) $150 \mathrm{~mm}$ of separation between Shed and Freezers (i.e., westward/seaward movement of the Shed relative to the Freezers), (S41.280584 ${ }^{\circ} \mathrm{E174.784705^{ \circ } , 2 2 N O V 1 6 ) .}$ 


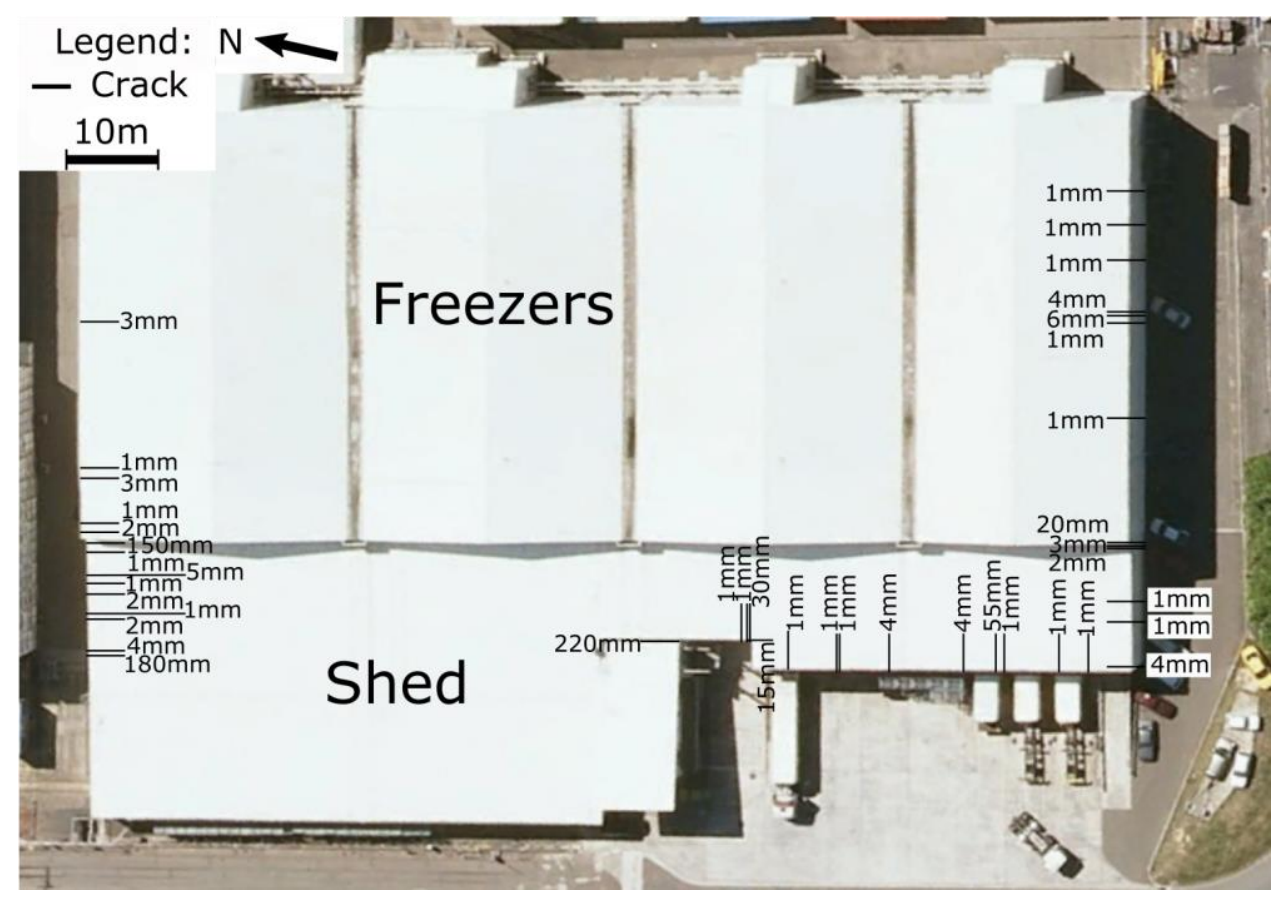

Figure 29: Location and width of lateral ground movement-induced cracks in the RC concrete walls at the base of the exterior building walls of the CS building. Crack openings are parallel to the respective wall.

Legend:

$\Leftrightarrow$ Joint separation

Settlement reference point

- Settlement relative too

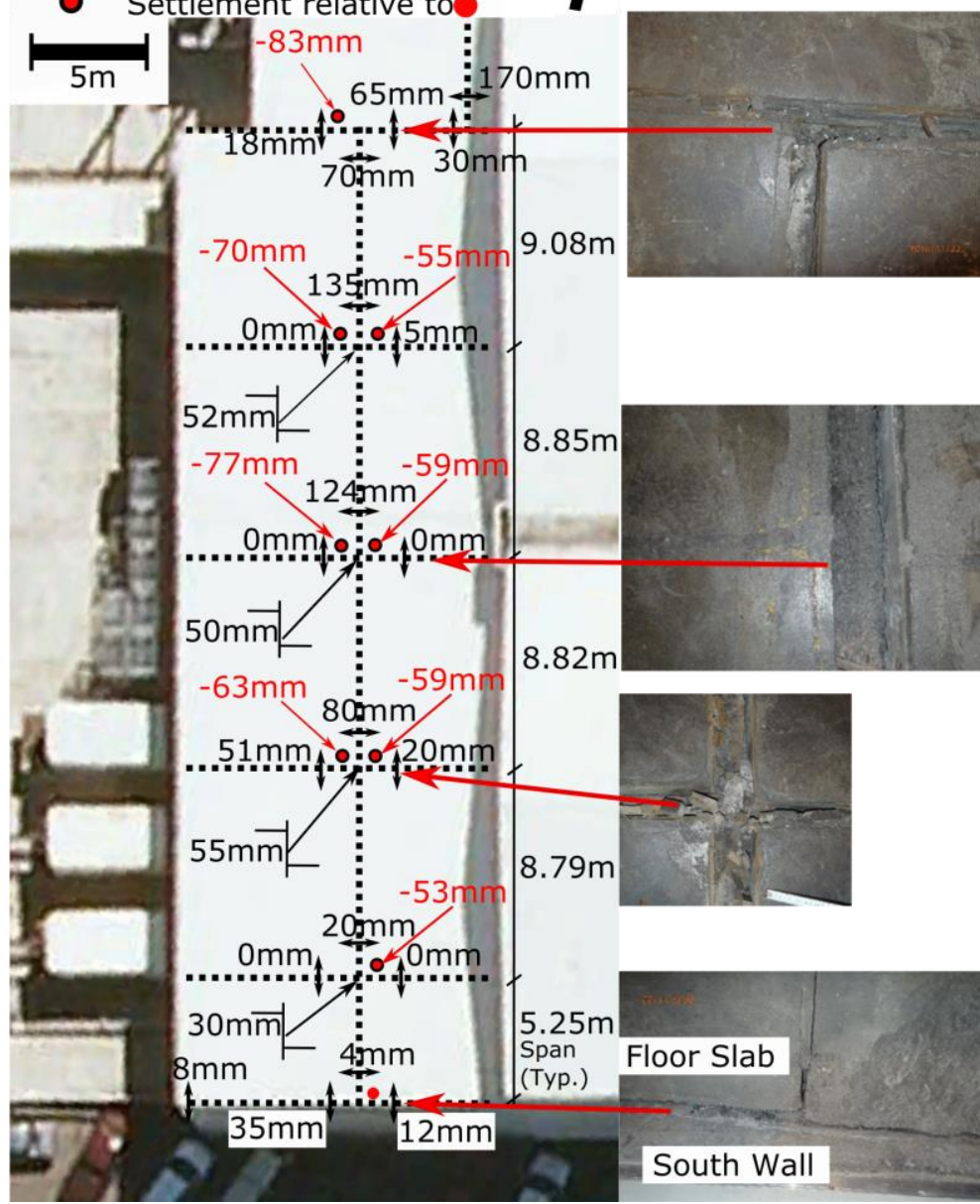

Figure 30: Southern part of Shed floor slab construction joint separation measurements. Photographs along right side of figure are of construction joints at which measurements were taken and are aligned vertically with each depicted joint. (Surveyed 


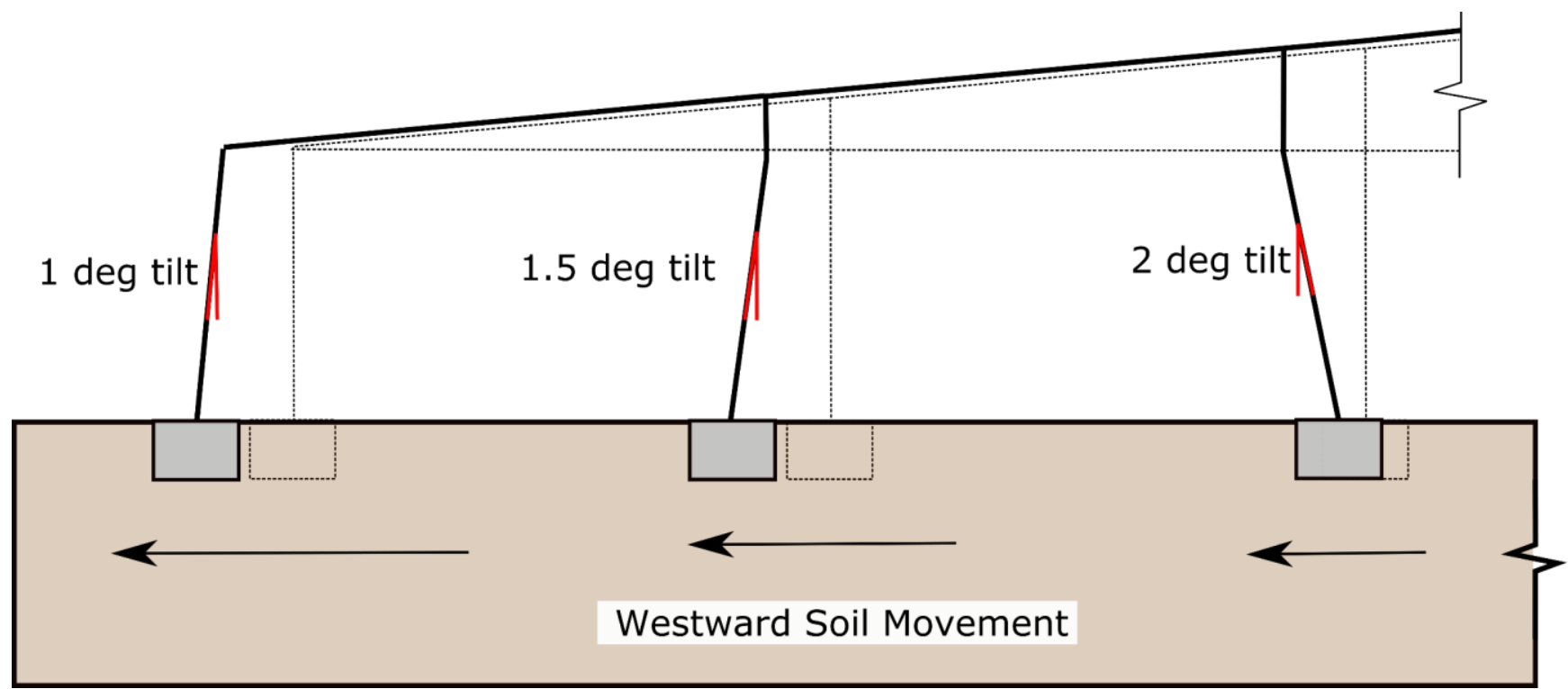

Figure 31: Schematic of deformation pattern of steel frame along the north wall of CS building (three west-most columns of the Shed; looking north from interior).
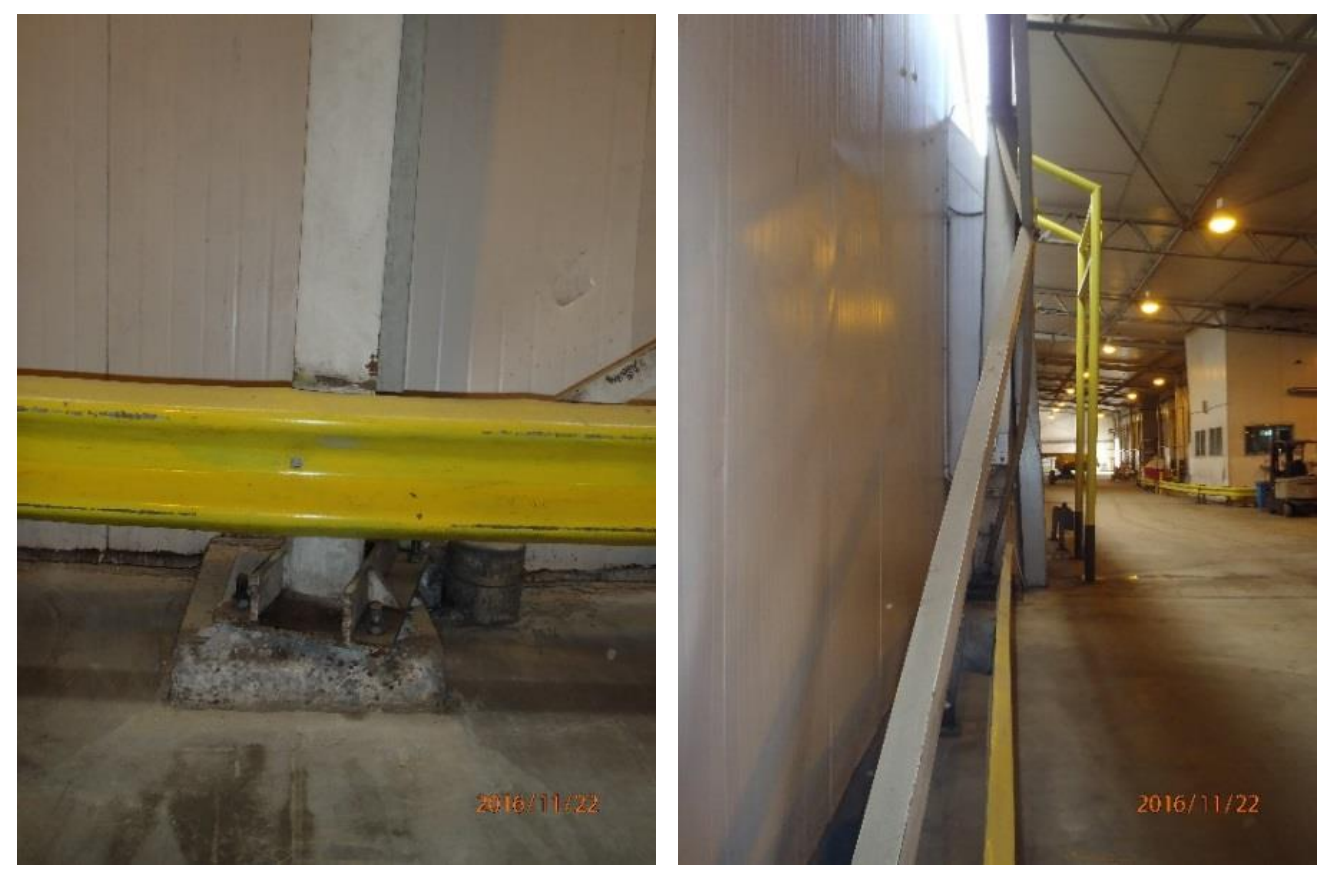

Figure 32: Internal east wall in northern part of the Shed, which shows column-pedestal connection failure due to rotation of the base of the column and buckling of concentric bracing. (Approx. at $S 41.280939^{\circ} \mathrm{E} 174.784778^{\circ}, 22 \mathrm{NOV16}$ ).

\section{Buildings on Deep Foundations}

\section{S39 Building}

The S39 building (see Figure 24) is supported on Frankie piles. The old buried mass concrete seawall (i.e., Old Seawall) runs parallel and adjacent to the southeast wall of the building. Additionally, along the southeast wall, a segment of the historic Fryatt Quay Wharf deck (Figure 3) was left intact. The ground to the south of the seawall and wharf settled $220 \mathrm{~mm}$ relative to the top of the wharf deck and the pile-supported building (Fig. 33a). Approximately 100 to $190 \mathrm{~mm}$ of settlement was observed along the southwest wall of the building (Figure 33b). On the northwest side of the building, the ground adjacent the building settled approximately $50-100 \mathrm{~mm}$ relative to the building. The
QuakeCoRE-GEER team was informed that the ground floor slab dropped $150 \mathrm{~mm}$ inside the building ( $\mathrm{T}+\mathrm{T}$ (2016), private communication).

\section{TC Building}

The TC building (see Figure 24) is immediately to the northwest of the S39 building, and is supported on driven RC piles. Liquefaction ejecta was observed along the short southwest wall of the building, and $150 \mathrm{~mm}$ of ground settlement relative to the building was measured. 

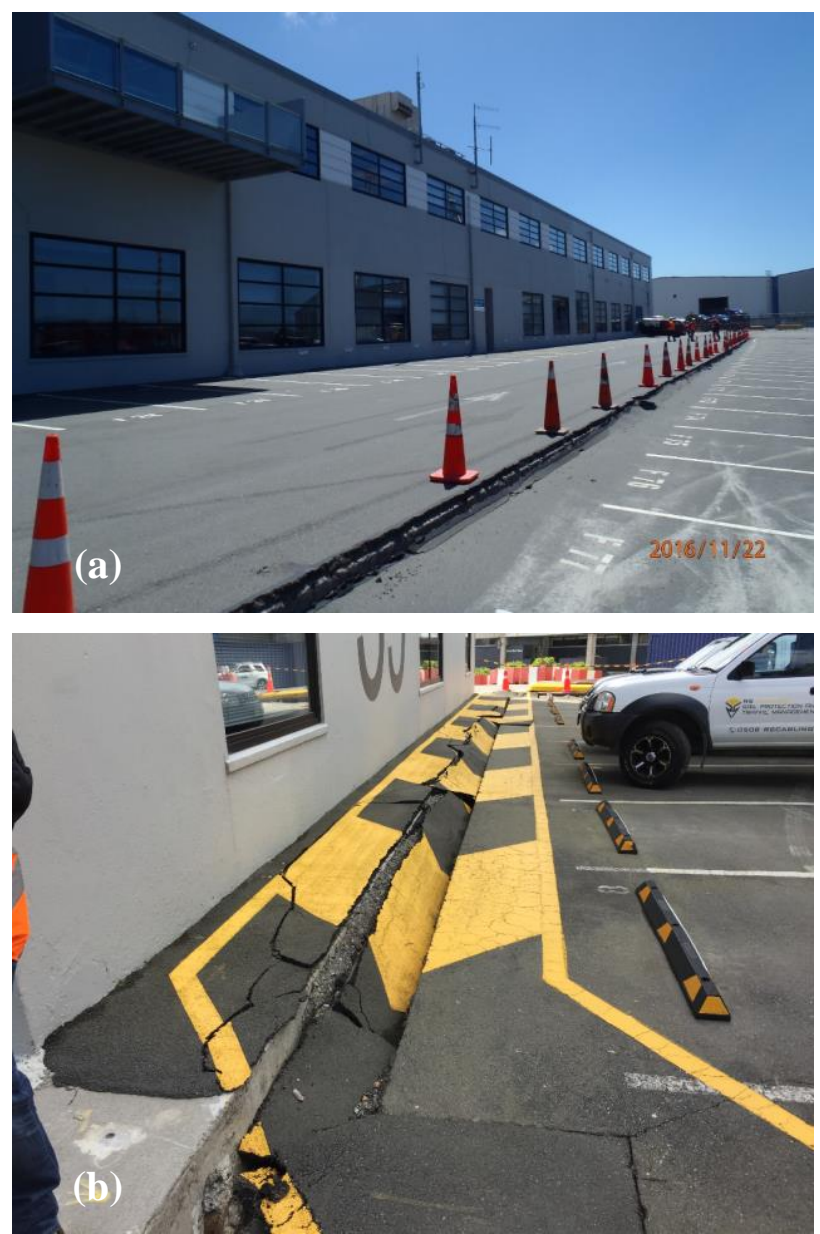

Figure 33: (a) Southeast side of Building S39 and a buried segment of the Fryatt Quay Wharf deck parallel to the building. Fill to the south of the buried mass concrete seawall/wharf settled $220 \mathrm{~mm}$ relative to the pile-supported building and wharf deck. (S41.277984 ${ }^{\circ} \mathrm{E} 174.785776^{\circ}$, 22NOV16), and (b) looking southeast along southwest wall of Building S39. Fill settled approximately $190 \mathrm{~mm}$ relative

to pile-supported building at the northwest corner of the building (shown on lower left corner of photo), and

magnitude of settlement decreased south-eastward along this wall. (S41.277994 $\left.{ }^{\circ} \mathrm{E} 174.785467^{\circ}, 17 \mathrm{NOV16}\right)$.

\section{S37 Building}

The western half of the S37 building (see Figure 24) is founded on the deck of the buried, partially demolished pile-supported Pipitea Wharf, and the east wall of the building is supported on piles. The precast seawall that formerly ran along the bulkhead of the Pipitea Wharf is now buried and runs south-to-north through about the centerline of the building. The ground floor slab not supported on piles, the old wharf deck, or the precast seawall settled up to $550 \mathrm{~mm}$ relative to these structures (Fig $34 \mathrm{a}$; the value is based on measurement from LiDAR scan for this building). The ground settled approximately $375 \mathrm{~mm}$ relative to the building along the exterior of the east wall of the S37 building (Figure 34b). Approximately $16 \mathrm{~m}$ west of the western wall of the S37 building, a buried row of piles from the old Pipitea Wharf protruded from the ground as the surrounding fill settled approximately $300 \mathrm{~mm}$ relative to the piles (Figure 17).

\section{S51 Building}

The S51 building (see Figure 24) is in the northeastern reclaimed land of CentrePort, which is an area reclaimed using hydraulically-placed dredged fill.
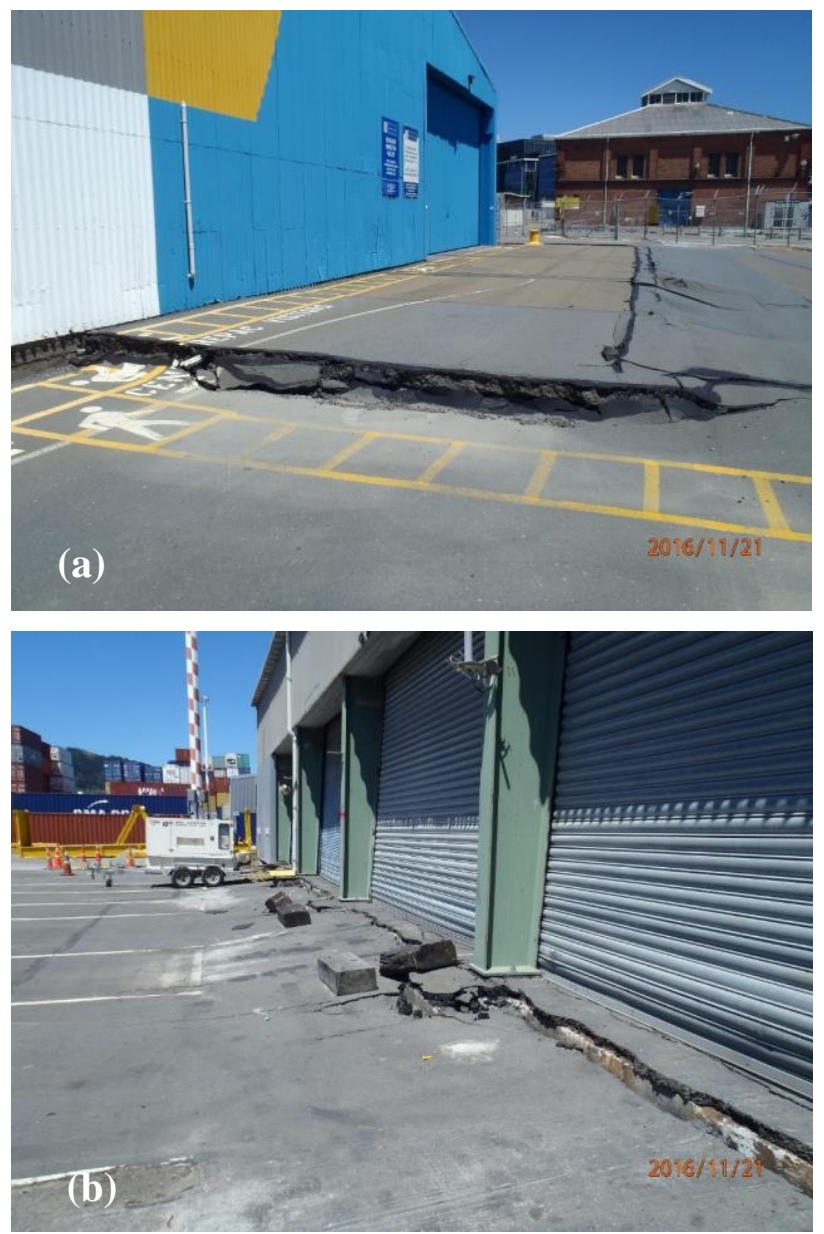

Figure 34: (a) Looking west across north wall of Building S37. Approximately $400 \mathrm{~mm}$ of differential settlement

between ground and deck of buried, pile-supported Pipitea

Wharf that supports the western side of the shed.

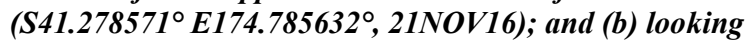
south along east wall of Building S37, which shows approximately $375 \mathrm{~mm}$ of differential settlement between fill and pile-supported east wall of the building. (S41.279065 E174.785787, 21NOV16).

The eastern wall of the building is founded on the pilesupported wharf, and the remainder of the building is founded on piles. The ground south of the building settled $230 \mathrm{~mm}$ relative to the wharf deck. Settlement magnitudes decreased from south to north, and only 10 to $20 \mathrm{~mm}$ of ground settlement was observed relative to the wharf in the surrounding ground north of the building. At the southern end of the building, the wharf that supports the eastern wall moved laterally eastward approximately $85 \mathrm{~mm}(35 \mathrm{~mm}$ crack at bulkhead and $50 \mathrm{~mm}$ crack $14.6 \mathrm{~m}$ west of bulkhead), which resulted in cracking of the southern wall near the wharf bulkhead. This equates to 85 $\mathrm{mm}$ of lateral movement over $14.6 \mathrm{~m}$ corresponding to a lateral strain of approximately $0.58 \%$. Additionally, several vertical cracks were observed in the western exterior walls of the building.

\section{$S$ Building}

The $\mathrm{S}$ building (see Figure 24) is a 5-storey reinforced concrete building founded on piles, which was built in 2006. The corners are on driven reinforced concrete piles while the interior columns are founded on cast-in-place concrete piles. No ground improvement was performed under the building. The building suffered structural damage, and is being investigated thoroughly by CentrePort. No signs of foundation damage were visible at the ground surface during the QuakeCoRE-GEER 
team visit though some level of distress in the ground adjacent to the building was evident. The ground settled 100 to $200 \mathrm{~mm}$ relative to the pile-supported building (Figure 35), in a relatively uniform fashion though some deviations from this pattern were also evident. Ground floor infill walls along the perimeter of the building were cracked in places, and the Level 1 floor slab pulled out and partially collapsed.

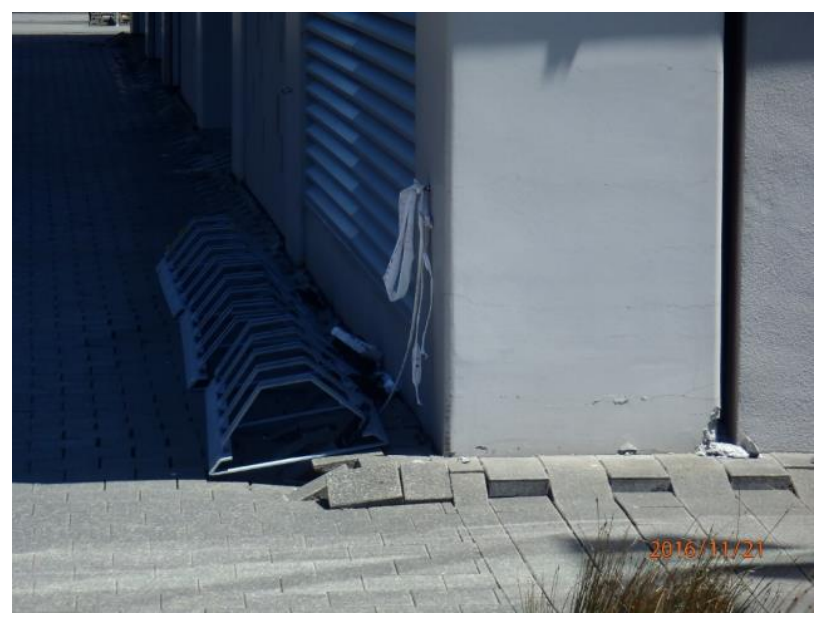

Figure 35: Looking west at southeast corner of the $S$ building at which fill settled approximately 100 to $200 \mathrm{~mm}$ relative to pile-supported building. ( $\$ 41.278285^{\circ}$ E174.784757, 21NOV16).

\section{B Building}

The B building (see Figure 24) is supported on piles with stone column ground improvement performed over the southeastern (seaward) half of the building footprint. The surrounding ground settled approximately 50 to $90 \mathrm{~mm}$ uniformly relative to the building (Figure 36). No other significant movements were observed.

\section{CONCLUSIONS}

Widespread liquefaction occurred in the end-dumped gravelly fills and hydraulically placed dredged sandy fills at the CentrePort of Wellington as a result of the 2016 Kaikoura earthquake. The liquefaction manifestation varied from traces of ejected soil and water on the pavement surface to larger volumes of ejecta with thicknesses of up to $150-200 \mathrm{~mm}$. The ejecta south of the Old Seawall consisted predominantly of gravelly soils including some cobble-size particles. The reclamation south of the Old Seawall was largely end-dumped gravelly fills. However, there were areas of sandy ejecta south of the Old Seawall. Sand ejecta were found largely north of the Old Seawall in the hydraulically placed sandy fills.

The liquefaction resulted in a substantial global (mass) settlement of the reclamation and lateral spreading towards the sea, which adversely affected wharf structures and buildings constructed on shallow and deep foundations. The settlement of the fill south of the Old Seawall was generally in the range from $200 \mathrm{~mm}$ to $500 \mathrm{~mm}$, while permanent lateral spreading displacements at the edges of the reclamation either reached or exceeded $1.0 \mathrm{~m}$.

Liquefaction-induced ground deformations and spreading caused the wharves to displace laterally and tilt-down towards the sea, and the wharf movements damaged their piles. In the zone affected by spreading, lateral ground extension and differential settlement damaged the CS building on shallow foundations. Buildings in areas of liquefaction-induced settlement without lateral extension performed significantly better. Buildings on shallow foundations settled more or less uniformly though some relative soil-foundation movements and ground distress were apparent along the perimeter of the building, whereas ground adjacent to pile-supported buildings settled typically in the range from about $100 \mathrm{~mm}$ to about 500 $\mathrm{mm}$ relative to the building.

\section{ACKNOWLEDGEMENTS}

Special thanks for the collaboration provided by the CentrePort Ltd. especially for allowing access to our team and making special arrangements for our multiple visits. We would like to acknowledge the great support and collaboration from Stuart Palmer, Richard Cole, Mike Jacka, and Sjoerd van Ballegooy, from Tonkin + Taylor, who as engineers for the CentrePort provided critical input and support in various phases of these efforts. Site access assistance through Hugh Cowan of the Earthquake Commission is sincerely appreciated. Use of results from aerial survey of Thorndon Reclamation and Wharf performed by Cardno is gratefully acknowledged.

The NZ team was principally supported by EQC Capability Grant at the University of Canterbury, and MBIE support provided for the 2016 Kaikoura Earthquake Reconnaissance. The US GEER team contributors were supported by the National Science Foundation (NSF) through the Geotechnical Engineering Program under Grants CMMI-1266418 and CMMI-1724866. Any opinions, findings, and conclusions or recommendations expressed in this material are those of the authors and do not necessarily reflect the views of the NSF. For more information visit the GEER website: www.geerassociation.org.
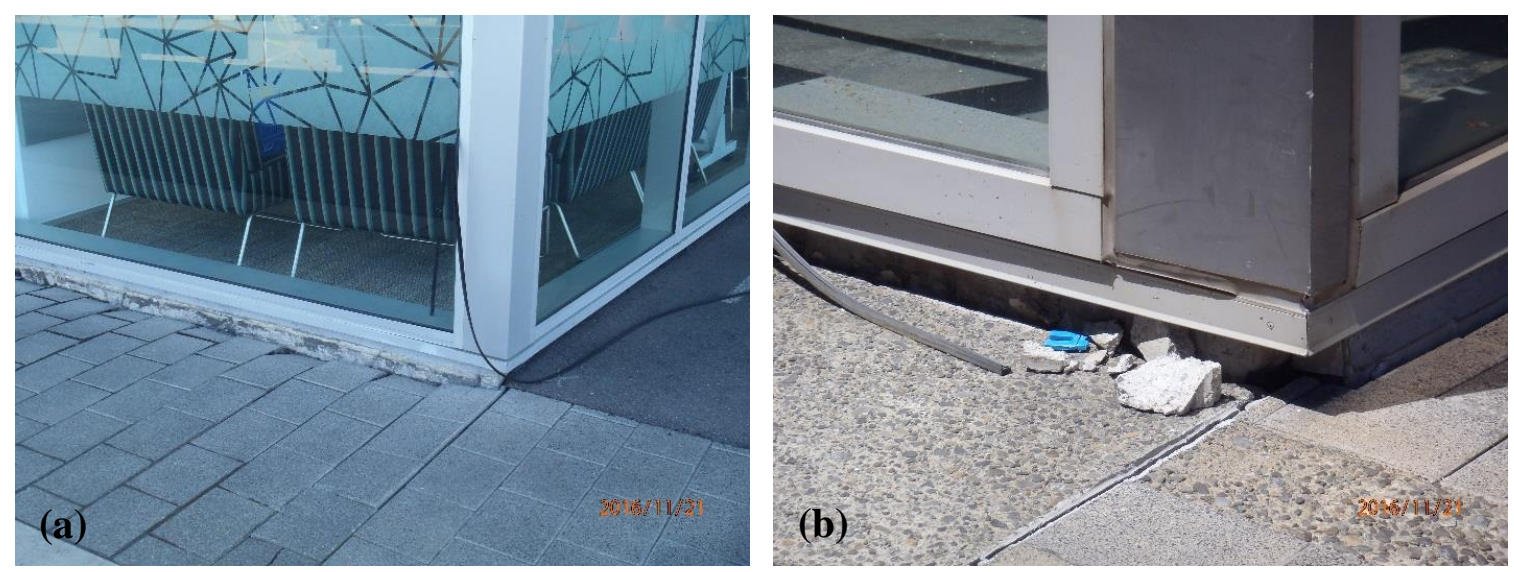

Figure 36: Ground settlement relative to the pile-supported B building at: (a) the southwest corner of the building with ground

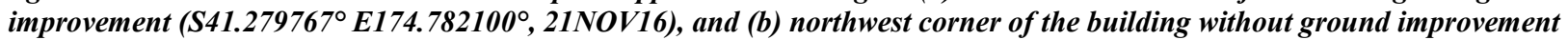
(S41.279419 $\left.{ }^{\circ} \mathrm{E} 174.781443^{\circ}, 21 \mathrm{NOV16}\right)$. 
The NZ-US QuakeCoRE-GEER team performed on-site reconnaissance on November 17, 20, 21, 22, 23 and 30, and December 1 and 2, 2016. Profs. Misko Cubrinovski, University of Canterbury, and Jonathan Bray, University of California, Berkeley, led these QuakeCoRE-GEER efforts and participated in the inspections on multiple occasions. Christopher de la Torre (UC) contributed to most of these inspections and compilation of the gathered data. Prof. Brendon Bradley (UC), Dr. Gabriele Chiaro (UC) and Dr. Liam Wotherspoon (UA) also were members of the early reconnaissance teams. All LiDAR scanning at CentrePort was performed and processed by Prof. Michael Olsen, a U.S. GEER team member from Oregon State University, with his student, Matthew O'Banion. Leica Geosystems, David Evans and Associates, and Maptek I-Site provided equipment and/or software utilized in this study. Particle-size analyses on the ejected soils were performed in the Geotechnical Laboratory of the University of Canterbury. This is QuakeCoRE publication number 0168.

\section{REFERENCES}

1 QuakeCoRE - GEER (2017). "Geotechnical Aspects of the 14 November 2016 Kaikoura (New Zealand) Earthquake". QuakeCoRE - GEER Reconnaissance Report. Editors: Cubrinovski and Bray.

2 Orense RP, Mirjafari Y, Asadi S, Naghibi M, Chen X, Altaf O and Asadi B (2017). "Liquefaction-Induced Damage in Wellington Waterfront Area Following the 2016 Kaikoura Earthquake". Bulletin of New Zealand Society for Earthquake Engineering, 50(2): 142-151.

3 Hutchison AJH (1973). "Reclamations in Wellington Harbour with special reference to recent developments". New Zealand Engineering, 15 August 1973, 217-224.

4 Tonkin \& Taylor Ltd. (2012). "Thorndon Container Wharf Seismic Assessment Geotechnical Factual Report". Prepared for CentrePort Limited. Ref No. 85369.001.

5 Anderson G (1984). "Fresh about the Cook Strait - An appreciation of Wellington Harbour". Methuen Publications, p.215.

6 Tonkin \& Taylor Ltd. (1998). "Proposed Coldstore Geotechnical Report". Prepared for CentrePort Limited. Ref No. 82363.

7 Tonkin \& Taylor Ltd. (2000). "CentrePort Shed $R$ Geotechnical Report". Prepared for CentrePort Limited. Ref No. 82787-01.
8 Tonkin \& Taylor Ltd. (2006). "Harbour Quays Development Factual Geotechnical Report, Revision 2". Prepared for CentrePort Wellington Limited. Ref No. 83725.004

9 Tonkin \& Taylor Ltd. (2014). "Thorndon Container Wharf Seismic Assessment Geotechnical Interpretive Report". Prepared for CentrePort Limited. Ref No. 85369.001.

10 Semmens S, Dellow GD and Perrin ND (2010). "It's Our Fault - Geological and Geotechnical Characterisation of the Wellington Central Business District". GNS Science Consultancy Report 2010/176. 52p.

11 Wellington Harbour Board (1936). "Historical Plan of Reclamations in the Port of Wellington (Port Nicholson)".

12 Bradley BA, Razafindrakoto HNT and Polak V (2017). "Ground motion observations from the 14 November 2016 Mw7.8 Kaikoura, New Zealand earthquake and insights from broadband simulations". Seismological Research Letters, 88(3): 740-756.

13 SNZ (2004). "NZS 1170.5: Structural Design Actions Part 5 Earthquake Actions - New Zealand". Standards New Zealand, Wellington, NZ.

14 Boulanger RW and Idriss IM (2012). "Probabilistic Standard Penetration Test-Based Liquefaction-Triggering Procedure". Journal of Geotechnical and Geoenvironmental Engineering, 138: 1185-1195

15 Boulanger RW and Idriss IM (2014). "CPT and SPT Based Liquefaction Triggering Procedures". Report No. UCD/CGM-14/01, Center for Geotechnical Modelling, Department of Civil and Environmental Engineering, University of California, Davis, April 2014.

16 Greater Wellington Regional Council: http://graphs.gw.govt.nz/?siteName=Wellington $\% 20$ at $\% 2$ $0 \mathrm{Te} \% 20 \mathrm{Papa} \&$ dataSource $=$ Rainfall\&interval $=1 \% 20 \mathrm{Hour}$ \&Alignment=1\%20Hour (Accessed 11 May 2017).

17 Ishihara K, Yoshida K and Kato M (1997). "Characteristics of lateral spreading in liquefied deposits during the 1995 Hanshin-Awaji earthquake". Journal of Earthquake Engineering, 1(1): 23-55.

18 Cubrinovski M and Robinson K (2016). "Lateral spreading: Evidence and interpretation from the 2010-2011 Christchurch earthquakes". Soil Dynamics and Earthquake Engineering, 91: 187-201. 